\title{
Selective Localization of Arc mRNA in Dendrites Involves Activity- and Translation-Dependent mRNA Degradation
}

\author{
Shannon Farris, ${ }^{2}$ Gail Lewandowski, ${ }^{1}$ Conor D. Cox,${ }^{2}$ and Oswald Steward ${ }^{1,2,3,4}$ \\ ${ }^{1}$ Reeve-Irvine Research Center and Departments of ${ }^{2}$ Anatomy and Neurobiology, ${ }^{3}$ Neurobiology and Behavior, and ${ }^{4}$ Neurosurgery, University of California, \\ Irvine, Irvine, California 92697
}

\begin{abstract}
Arc is an immediate early gene that is unique among neuronal mRNAs because its transcripts are transported into dendrites and accumulate near activated synapses, presumably to be translated locally. These qualities pose Arc as playing an important, yet not fully understood, role in the activity-dependent modifications of synapses that are thought to underlie memory storage. Here we show in vivo in rats that newly synthesized Arc mRNA accumulates at activated synapses and that synaptic activity simultaneously triggers mRNA decay that eliminates Arc mRNA from inactive dendritic domains. Arc mRNA degradation occurs throughout the dendrite and requires both NMDA receptor activation and active translation. Synaptic activation did not lead to decreases in another dendritic mRNA $(\boldsymbol{\alpha} C a M K I I)$, indicating that there is not a general activation of mRNA degradation in dendrites. These data reveal a novel mechanism for controlling mRNA distribution within dendrites and highlight activity-dependent mRNA degradation as a regulatory process involved in synaptic plasticity.
\end{abstract}

Key words: Arc/Arg3.1; mRNA degradation; mRNA localization; NMDA receptors; protein synthesis; synapse

\section{Introduction}

Long-lasting changes in synaptic function that underlie memory storage are induced by particular patterns of synaptic activity and involve time-dependent processes that require mRNA transcription and synthesis of particular proteins (Nguyen and Kandel, 1996; Kandel, 2001). Unique among the genes upregulated in response to neuronal activity is the immediate early gene (IEG) Arc (activity-regulated cytoskeletonassociated protein, also known as activity regulated gene 3.1). Arc transcription is induced by synaptic activity or learning experiences, and its mRNA is rapidly transported into dendrites (Link et al., 1995; Lyford et al., 1995; Guzowski et al., 1999). Arc mRNA accumulates near recently activated synapses, presumably to undergo local translation (Steward et al., 1998). Manipulations that disrupt Arc synthesis, for example, local injection of antisense oligonucleotides into the hippocampus, blocks late-phase LTP and disrupts consolidation of hippocampal-dependent memory (Guzowski et al., 2000; Messaoudi et al., 2007). These features implicate Arc in coupling synaptic activity to transcription- and translationdependent forms of synaptic plasticity.

Received Nov. 19, 2013; revised Jan. 9, 2014; accepted Feb. 10, 2014.

Author contributions: S.F. and 0.S. designed research; S.F., G.L., and C.D.C. performed research; S.F., G.L., and C.D.C. contributed unpublished reagents/analytic tools; $S$.F. and $0 . S$. analyzed data; $S . F$. and $0 . S$. wrote the paper.

This work was supported by National Institutes of Health Grant NS-12333 (0.S.) and National Science Foundation Grant DGE-1321846 (C.D.C.). Imaging analyses were performed in the microscopy core of the Center for Autism Research and Treatment, University of California, Irvine. We thank Kelli Yee and Jamie Mizufuka for technical assistance.

Correspondence should be addressed to Dr. Oswald Steward, Reeve-Irvine Research Center, University of California, Irvine, 1105 Gillespie Neuroscience Research Facility, Irvine, CA 92697-4265. E-mail: osteward@uci.edu.

DOI:10.1523/JNEUROSCI.4944-13.2014

Copyright $\odot 2014$ the authors $\quad 0270-6474 / 14 / 344481-13 \$ 15.00 / 0$
mRNA levels depend on the balance between transcription and mRNA degradation. Under basal conditions, $A r c$ is expressed at low levels, and synaptic activation sufficient to activate NMDA receptors (NMDARs) triggers Arc mRNA transcription. Arc mRNA is short lived, but little is known about how Arc mRNA degradation is regulated and whether degradation is regulated by synaptic activity.

In previous studies (Steward and Worley, 2001), we showed that, when Arc mRNA is already present in dendrites, subsequent synaptic activation causes Arc mRNA to accumulate near activated synapses. As Arc mRNA accumulates at activated synapses, it disappears from inactive portions of the dendrite. We proposed two possible mechanisms for this change in distribution: (1) Arc mRNA that is already in dendrites could move from inactive to active dendritic domains; and (2) synaptic activation might trigger degradation of Arc mRNA in inactive domains, for example, via translation-dependent decay (Giorgi et al., 2007).

Here, we assess in vivo the relationship between the selective targeting of $A r c$ mRNA to activated synapses and depletion of $A r c$ mRNA in non-activated dendritic domains. We show that Arc mRNAs accumulating at activated synapses are in fact not relocalized mRNAs but rather are newly transcribed mRNAs being transported from the cell body. We further show that, in addition to causing Arc mRNA to localize at activated synapses, synaptic stimulation triggers Arc mRNA degradation throughout dendrites, that both localization and degradation depend on NMDAR activation, and that degradation is blocked by inhibiting protein synthesis (consistent with a translation-dependent mechanism). We also show that another mRNA that is present in dendrites constitutively, $\alpha C a M K I I$, is not depleted after strong synaptic activation. However, $\alpha C a M K I I$ mRNA does localize to activated synapses, indicating that there is mRNA transport to 
activated synapses but that the mRNA degradation mechanism is selective for Arc.

\section{Materials and Methods}

Experimental animals were adult female Sprague Dawley and Long-Evans rats. All procedures involving live animals were approved by the University of California, Irvine Animal Care and Use Committee.

In vivo neurophysiological techniques and stimulation paradigms. Our basic approach involved delivery of a single electroconvulsive seizure (ECS) to induce Arc expression, followed by acute neurophysiological recording as described previously (Steward and Worley, 2001). ECSs were induced in unanesthetized rats by delivering alternating current (60 $\mathrm{Hz}, 40 \mathrm{~mA}$ for $0.5 \mathrm{~s}$ ) through ear clips. Anesthesia was induced immediately after ECS by intraperitoneal injection of $20 \%$ urethane $(0.2 \mathrm{~g} / 100 \mathrm{~g}$ body weight). The rats were placed in a stereotaxic apparatus, and constant body temperature was maintained by placing animals on a waterjacket heating pad throughout the experiment. Holes were drilled into the skull at placements for the recording and stimulating electrodes. The stimulating electrode (an insulated tungsten microelectrode) was positioned stereotaxically so as to selectively activate one side of the medial perforant path (PP; $4 \mathrm{~mm}$ lateral from the midline and $1 \mathrm{~mm}$ anterior to the transverse sinus). Electrode depths $(\sim 3-4 \mathrm{~mm}$ deep from the cortical surface) were empirically determined to obtain a maximal evoked response in the dentate gyrus at minimal stimulus intensity. A pulled glass micropipette served as a recording electrode, was filled with $0.9 \%$ saline, and positioned in the cell body layer of the dorsal blade of the dentate gyrus ( $1.8 \mathrm{~mm}$ lateral from the midline and $3.5 \mathrm{~mm}$ posterior to bregma). The recording electrodes were positioned in the cell body layer of the dentate gyrus ( $\sim 3-3.5 \mathrm{~mm}$ deep from the cortical surface) based on the evoked responses generated by PP stimulation. Single test pulses were then delivered at a rate of $0.1 \mathrm{~s}$ for a minimum of $20 \mathrm{~min}$ to determine baseline response amplitude.

Drugs were infused locally into the dentate gyrus by switching out the saline electrode for one filled with one of the following drugs (all purchased from Sigma-Aldrich and used at maximum solubility in saline): cycloheximide (CHX; $10 \mathrm{mg} / \mathrm{ml}), \mathrm{MK}-801(10 \mathrm{mg} / \mathrm{ml})$, and actinomycin D-mannitol (ActD; $2 \mathrm{mg} / \mathrm{ml}$ ). The tips of the micropipette electrodes were broken back to generate a tip of $\sim 75-100 \mu \mathrm{m}$ in diameter to allow greater drug diffusion and were stereotaxically repositioned above the cell body layer in the molecular layer. The micropipettes were left in place for $30 \mathrm{~min}$ before stimulation to allow diffusion and record baseline responses with the drug. The area affected by the drugs depended on the molecular properties of each drug (see Results). Two hours after the ECS was delivered, high-frequency stimulation was delivered to the PP (trains of eight pulses at $400 \mathrm{~Hz}$ at a rate of $0.1 \mathrm{~s}$ for varying amounts of time; see Results). Immediately after PP stimulation, rats received a lethal dose of Euthasol and were decapitated, and the brains were removed and flash frozen in isopentane (chilled to $-20^{\circ} \mathrm{C}$ in a dry ice and ethanol bath). Alternatively, in some experiments (see Results), rats were transcardially perfused with $4 \%$ paraformaldehyde.

In situ hybridization. Fluorescent in situ hybridization (FISH) was performed on $20-\mu \mathrm{m}$ cryostat-cut coronal sections prepared from flashfrozen brains as described in detail previously (Guzowski et al., 1999, Vazdarjanova and Guzowski, 2004). Briefly, $\operatorname{Arc}$ and $\alpha$ CaMKII riboprobes were generated using the Ambion MaxiScript kit with premixed RNA labeling nucleotide mix containing digoxigenin-labeled UTP (Roche). Brain sections were incubated at $56^{\circ} \mathrm{C}$ with labeled antisense riboprobe (1-2 ng/ $\mu \mathrm{l})$ for 14-16 h. After treatment with RNase A (10 $\mu \mathrm{g} / \mathrm{ml}$; Sigma) and extensive washes, including a stringency wash $(0.5 \times$ SSC, $30 \mathrm{~min}$ at $56^{\circ} \mathrm{C}$ ), the brain sections were incubated with a horseradish peroxidase (HRP)-conjugated antibody to digoxigenin (1:400; Roche). The HRP was detected using the Tyramide Signal Amplification Fluorescence (TSA-Cy3) kit from PerkinElmer Life and Analytical Sciences. Finally, cellular nuclei were stained with DAPI, and the slides were coverslipped using Vectashield mounting media (Vector Laboratories).

RNAscope in situ hybridization (ISH) was performed on $20-\mu \mathrm{m}$ cryostat-cut coronal sections prepared from flash-frozen rat brains. Tissue sections were fixed in $4 \%$ paraformaldehyde for $1 \mathrm{~h}$ at $4^{\circ} \mathrm{C}$, followed by serial dehydration steps in 50, 70, and 100\% ethanol. Sections were air dried at room temperature and then processed using the RNAscope Fresh Frozen Multiplex Fluorescent kit according to the protocol of the manufacturer (Advanced Cell Diagnostics). Target probe hybridization and signal amplification were performed as described previously (Wang et al., 2012).

Non-isotopic colorimetric ISH was performed as described previously (Wallace et al., 1998; Steward and Worley, 2001). Briefly, paraformaldehyde-fixed brains were sectioned in the coronal plane at 40 $\mu \mathrm{m}$ using a vibratome. Sections were postfixed in $4 \%$ paraformaldehyde, permeabilized with proteinase $\mathrm{K}$, and then hybridized with hydrolyzed digoxigenin-labeled Arc or CaMKII cRNA (1-2 ng/ $\mu$ l for $16-18 \mathrm{~h}$ at $\left.56^{\circ} \mathrm{C}\right)$. After treatment with RNase A $(10 \mu \mathrm{g} / \mathrm{ml})$ and extensive washes, including a stringency wash $\left(0.1 \times \mathrm{SSC}, 2 \mathrm{~h}\right.$ at $\left.55^{\circ} \mathrm{C}\right)$, the probe was detected with anti-digoxigenin Fab (1:1000; Roche), then colorized overnight using NBT/BCIP, and coverslipped under Kaiser mounting media.

Immunohistochemistry was performed as described previously (Huang et al., 2007) using coronal sections from perfusion-fixed brains as detailed above. Antigen retrieval was achieved by placing sections in microfuge tubes filled with nanopure water and boiling for $5 \mathrm{~min}$. Sections were washed in PBS and blocked with TSA blocking buffer (PerkinElmer Life and Analytical Sciences) before overnight incubation with affinity purified anti-Arc (1: 1000; Synaptic Systems). The tissue was washed in PBS and then was incubated with goat anti-rabbit Alexa Fluor-488 for direct immunofluorescent detection (1:250; Invitrogen).

Quantification of FISH signal. Quantification of fluorescence intensity or optical density across cell body and molecular layers was done using $20 \times 8$-bit grayscale images acquired at the same exposure on an epifluorescence microscope. Using NIH ImageJ software, a line region of interest (ROI) was measured to be the length of the cell body layer and the dendritic laminae (250-300 $\mu \mathrm{m}$ in length). This ROI was saved and used for each case and was aligned perpendicular to the cell body layer so that the middle molecular layer was positioned in the middle of the line at $150 \mu \mathrm{m}$ for $300 \mu \mathrm{m}$ ROIs and $125 \mu \mathrm{m}$ for 250 $\mu \mathrm{m}$ ROIs. This ensured that, despite differences in the widths of cell body layers, the region of stimulation (the middle molecular layer) was aligned across sections and rats. Non-isotopic colorimetric ISH images acquired in bright field were inverted so that higher density equated to a greater intensity value. Line intensities were measured every $50 \mu \mathrm{m}$ along the length of the $20 \times$ image (usually $\sim 10$ line measurements per image). The intensity value for each point in the line ROI was averaged across the total number of line measurements per image to obtain an average value for each $10 \mu \mathrm{m}$ point along the line ROI (from $0 \mu \mathrm{m}$ to 250 or $300 \mu \mathrm{m}$ ) for each section. These average line ROI values were then averaged across rats to generate an "average fluorescence intensity (or optical density) versus distance" graph that represents the average of $n$ (number of rats) and presented as mean \pm SEM.

Quantitative analyses of Arc puncta. Sections processed for FISH were imaged across the molecular layer of the dentate gyrus at $63 \times$ using a confocal microscope, keeping all acquisition parameters constant. The size and number of Arc-positive puncta were determined using NIH ImageJ particle analysis software. Briefly, the images were overlaid using DAPI, and an ROI was determined so as to count each Arc puncta only once. The entire image was then thresholded to subtract background and watershed to segment individual Arc puncta. The ROI was then cropped out of the original image and subjected to particle analysis. The number and size of $A r c$ puncta were averaged across three sections per layer from one animal.

Quantitative analyses of $\alpha$ CaMKII and Arc puncta colocalization from RNAscope sections. Analyses were performed on one rat that received $2 \mathrm{~h}$ PP stimulation to allow maximal mRNA localization. Tissue was imaged using a Leica DM6000 epifluorescence microscope equipped with an Orca-ER charge-coupled device camera (Hamamatsu). Individual image $Z$-stacks were collected at $63 \times$ (Plan-Apochromat, numerical aperture 1.4) from the dorsal blade of the dentate gyrus. The sample field encompassed $136 \times 105 \mu \mathrm{m}$ in the $x-y$ plane, and $Z$-stacks were collected across a depth of $6 \mu \mathrm{m}$ at $0.2 \mu \mathrm{m}$ steps. Sample fields were collected for the cell body, inner, and middle molecular layers for the ipsilateral and contralateral sides, keeping acquisition parameters constant. The following image 


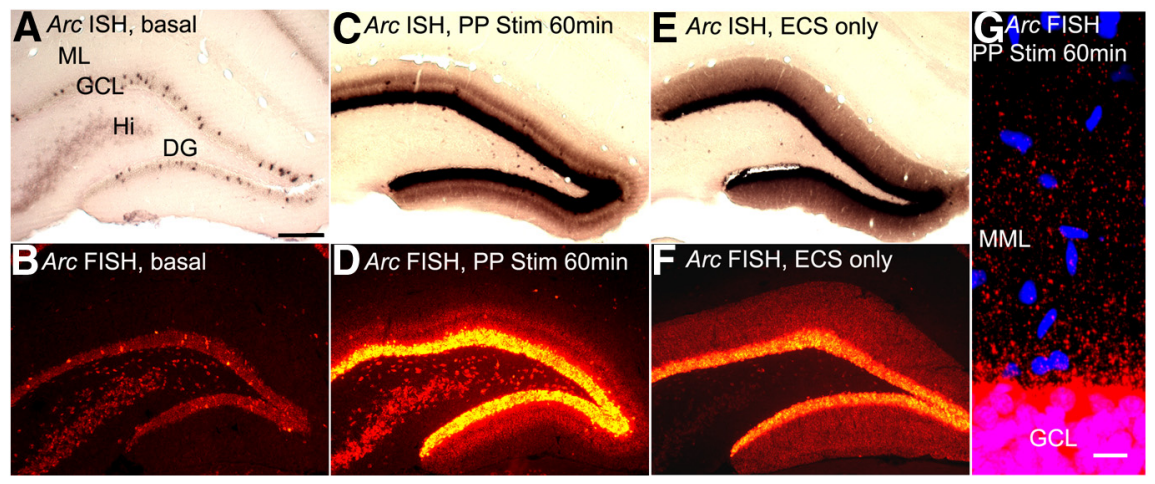

Figure 1. Assessment of Arc mRNA distribution in the dentate gyrus using colorimetric ISH versus FISH. $A, C, E, \operatorname{Arc~mRNA}$ detected using colorimetric ISH. $\boldsymbol{B}, \boldsymbol{D}, \boldsymbol{F}, \mathbf{G}, \operatorname{ArcmRNA}$ detected using FISH. $\boldsymbol{A}, \boldsymbol{B}$, Basal levels of $\operatorname{ArcmRNA}$ in the dentate gyrus. Notice only a minimal number of granule cells show high Arc expression. $C, D$, Arc expression after $1 \mathrm{~h}$ PP stimulation. Notice the band of Arc mRNA localizing in the middle molecular layer, the activated laminae. $E, F$, Arc expression $3 \mathrm{~h}$ after ECS. Notice that all granule cells are densely labeled as well as the diffuse distribution of Arc mRNA reaching the distal tips of dendrites. G, High-magnification image of fluorescent Arc mRNA particles after $1 \mathrm{~h}$ PP stimulation, in which Arc $\mathrm{MRNA}$ is labeled in red and nuclei in blue. DG, Dentate gyrus; Hi, hilus; GCL, granule cell layer; ML, molecular layer; MML, middle molecular layer. Scale bars: $A, 200 \mu \mathrm{m} ; \mathbf{G}, 25 \mu \mathrm{m}$.

a Pco.edge scientific Complementary MetalOxide-Semiconductor camera. Individual image $Z$-stacks were collected at $63 \times$ (PlanApochromat, numerical aperture 1.4) from the striatum radiatum of the hippocampus CA1. The sample field encompassed $264 \times 223 \mu \mathrm{m}$ in the $x-y$ plane, and $Z$-stacks were collected across a depth of $5 \mu \mathrm{m}$ at $0.5 \mu \mathrm{m}$ steps. Images were deconvolved using blind-itertive $3 \mathrm{D}$ deconvolution on Autoquant X2 using five iterations at high noise settings. The following image processing steps were done using NIH ImageJ (now FIJI; National Institutes of Health); $Z$-stack images were collapsed to projection images and converted to 8-bit grayscale. Every image was threshold to the same value (15-255 BW) to subtract background and separate individual particles. Images were subjected to particle analysis, and one-way ANOVA statistics were performed using Prism, in which each group (home cage-saline, home cage-CHX, and EE-saline) was compared with EE-CHX using uncorrected Fisher's least significant difference test $(\alpha=0.05)$.

processing steps were done using NIH ImageJ. Each DAPI, Arc and CaMKII image underwent contrast enhancement to $0.5 \%$ saturated pixels. A $75 \times 75 \mu \mathrm{m}$ ROI was positioned to maximize puncta number and limit granule cell bodies. The ROI was cropped out of the processed image, thresholded to eliminate signal present in fiber tracts (background), and then subjected to particle analysis. The output file was overlaid onto the merged image and individual processed image (inverted to better visualize puncta), and the number of colocalized puncta was determined manually for the stimulated side only, for each sample field (cell body, inner, and middle molecular layers), across one animal.

Quantification of cell body intensities using intronic and RNAscope probes. DAPI and Cy 3 images at $40 \times$ magnification were taken of the ipsilateral and contralateral granule cell bodies on the dorsal blade of the dentate gyrus. Then, using NIH ImageJ software, the DAPI images were subjected to a Gaussian blur (radius of 10) and then thresholded to outline the entire dentate granule cell layer, which was selected and saved using the magic-wand tool. The outlines of the granule cell layer were superimposed onto the $\mathrm{Cy} 3$ images, and the mean fluorescence intensity over the cell layer was determined. A background measure was taken from a circular region positioned in the hilus in which there were no Arc-positive neurons, and this background value was subtracted from the mean fluorescence over the granule cell body layer. Ipsilateral and contralateral values were averaged across three rats that received ECS-PP stimulation.

Unsupervised learning paradigm. Adult female Long-Evans rats were introduced in pairs into a $62 \mathrm{~cm}^{2}$ open field filled with plastic objects (children's toys). Before the experience, rats were housed two to three per cage, and two rats from different cages were paired during the experience. Rats were allowed to explore for $15 \mathrm{~min}$, and then one of the pair received $\mathrm{CHX}(20 \mathrm{mg} / \mathrm{kg}$, i.p.) and the other received saline. Rats were returned to the enriched environment (EE) for $1 \mathrm{~h}$. Rats decreased exploratory activity over time, so during the last $30 \mathrm{~min}$, the rats were picked up and moved if they remained in the same location for more than $\sim 2-3 \mathrm{~min}$. At the end of the experience, rats were killed with Euthasol, and brains were quickly removed and frozen together in a single block on the chuck of a cryostat. To assess possible effects of CHX on basal Arc expression, rats were housed two per cage, and one rat of the pair received CHX and the other received saline. Both rats were killed $1 \mathrm{~h}$ after injection, and brains were collected and frozen as above. The blocks containing pairs of brains were sectioned at $20 \mu \mathrm{m}$ on a cryostat and were stored at $-80^{\circ} \mathrm{C}$. Slides from all cases containing sections through the middle part of the dorsal hippocampus were run at the same time for $\mathrm{ArcFISH}$ as described above. To confirm blockade of $A r c$ protein synthesis, adjacent sections were also prepared for ARC immunohistochemistry.

Particle quantification for unsupervised learning tissue. Tissue was imaged using a Leica DMI6000B epifluorescence microscope equipped with
Plasmids. The plasmid used to generate Arc antisense riboprobe was against the full-length cDNA ( $3 \mathrm{kbp}$ ) of the rat Arc transcript described in detail by Lyford et al. (1995). The intronic Arc probe was a generous gift from John Guzowski (University of California, Irvine, Irvine, CA). The plasmid used to generate the $\alpha$ CaMKII antisense riboprobe was kindly provided by Dr. Howard Schulman (SurroMed). The following probes were purchased from Advanced Cell Diagnostics and used with the RNAscope fluorescent multiplex reagent kit: Rn-Arc-5p (catalog \#317066), Rn-Arc-3p-C2 (catalog \#317076-C2), and Rn-Camk2a-C3 (catalog \#317081-C3). The Arc 5' probe was designed against nucleotides $226-$ 1186 in the mRNA sequence, the Arc 3' probe was designed against nucleotides 1519-2621, and the $\alpha$ CaMKII probe was designed against nucleotides $180-1347$.

\section{Results}

\section{Assessment of Arc mRNA distribution using FISH}

Our previous studies used non-isotopic ISH to assess induction and dendritic transport of $A r c$ mRNA and localization at active synapses. Because this histochemical protocol produces a precipitation reaction product with low spatial resolution, these methods do not reveal the discrete packets in which Arc mRNA is transported. Here, we use a sensitive FISH technique that allows visualization of individual Arc mRNA particles in vivo (Guzowski et al., 1999).

Like other IEGs, Arc is expressed at low levels under basal conditions. In the dentate gyrus, a few neurons scattered throughout the granule cell layer express $A r c$ at high levels, but most granule cells are not labeled (Fig. 1A,B). When Arc transcription is induced in neurons, $\operatorname{Arc}$ mRNA is first evident in two distinct spots in the nucleus (transcription foci on the two chromosomes). Within minutes, Arc mRNA particles appear in the cytoplasm and, over time, move into dendrites (Guzowski et al., 1999). High-frequency stimulation of the PP induces Arc expression in virtually all granule cells, and, if stimulation continues as Arc mRNA moves into dendrites, Arc mRNA accumulates selectively in the region of activated synapses and does not reach the distal dendritic lamina (Fig. $1 C, D)$. ECSs also strongly induce Arc transcription, but in this case, Arc mRNA particles are transported throughout dendrites (Wallace et al., 1998; Fig. 1 E,F). 
Synaptic stimulation that causes Arc mRNA to localize at activated synapses depletes Arc mRNA from inactive domains

We showed previously that, when Arc mRNA is present at high levels throughout dendrites as a result of ECS, subsequent high-frequency stimulation of the PP causes $\operatorname{Arc}$ mRNA to accumulate near active synapses and disappear from inactive dendritic domains (Steward and Worley, 2001). Figure 2 confirms these results using FISH. In this experiment, rats received an ECS, and, 2 h later when Arc mRNA is distributed throughout dendrites, high-frequency stimulation was delivered to the PP. On the nonstimulated side, Arc mRNA was distributed throughout dendrites (Fig. 2A). With different periods of PP stimulation $(15,30$, and $60 \mathrm{~min}$ ), the distribution of Arc mRNA changed progressively so that the mRNA was selectively localized in the activated dendritic domain (Fig. 2B) with a distribution that is indistinguishable from what is seen after PP stimulation alone (Fig. 1C,D).

To quantify changes in $A r c$ mRNA distribution, levels of Arc mRNA were assessed by measuring fluorescence intensity across the granule cell layer and molecular layer. Importantly, the contralateral side (ECS-only) served as an internal control for the amount of Arc mRNA that would be present if no stimulation had occurred. After 15 min of PP stimulation, a band of Arc mRNA is evident in the activated lamina. In Figure 2, $C$ and $D$ illustrate the pattern of labeling on the control and stimulated sides in one rat, and $I$ illustrates the quantitative assessment from four rats. After $30 \mathrm{~min}$ of PP stimulation, the band of Arc mRNA was more distinct (Fig. $2 E, F$ ), and quantitative analyses from five rats reveals that this is mainly attributable to decreases in Arc mRNA levels in the non-activated, inner and outer regions compared with the activated region and the contralateral ECS-only control (Fig. 2J). The depletion in the non-activated regions was even more pronounced after $60 \mathrm{~min}$ of $\mathrm{PP}$ stimulation (Fig. 2G,H; quantitative analysis from six rats is illustrated in Fig. $2 K$ ).

To provide a statistical assessment of these changes at the 60 min time point, we calculated the average fluorescence intensity at four measuring sites: (1) the cell body layer; (2) the trough of labeling in the inner molecular layer; (3) the peak of labeling in the middle molecular layer; and (4) at a point $250 \mu \mathrm{m}$ from the edge of the cell body layer (Fig. $2 K$, arrows). The bar graph in Figure $2 L$ illustrates the average values across six rats. The decreases in fluorescence intensity in the non-activated inner and outer molecular layers were statistically significant (Wilcoxon's signed-rank test, $p<0.025$ and 0.001 for inner and outer regions, respectively; $n=6$ rats). Thus, the selective pattern of localization
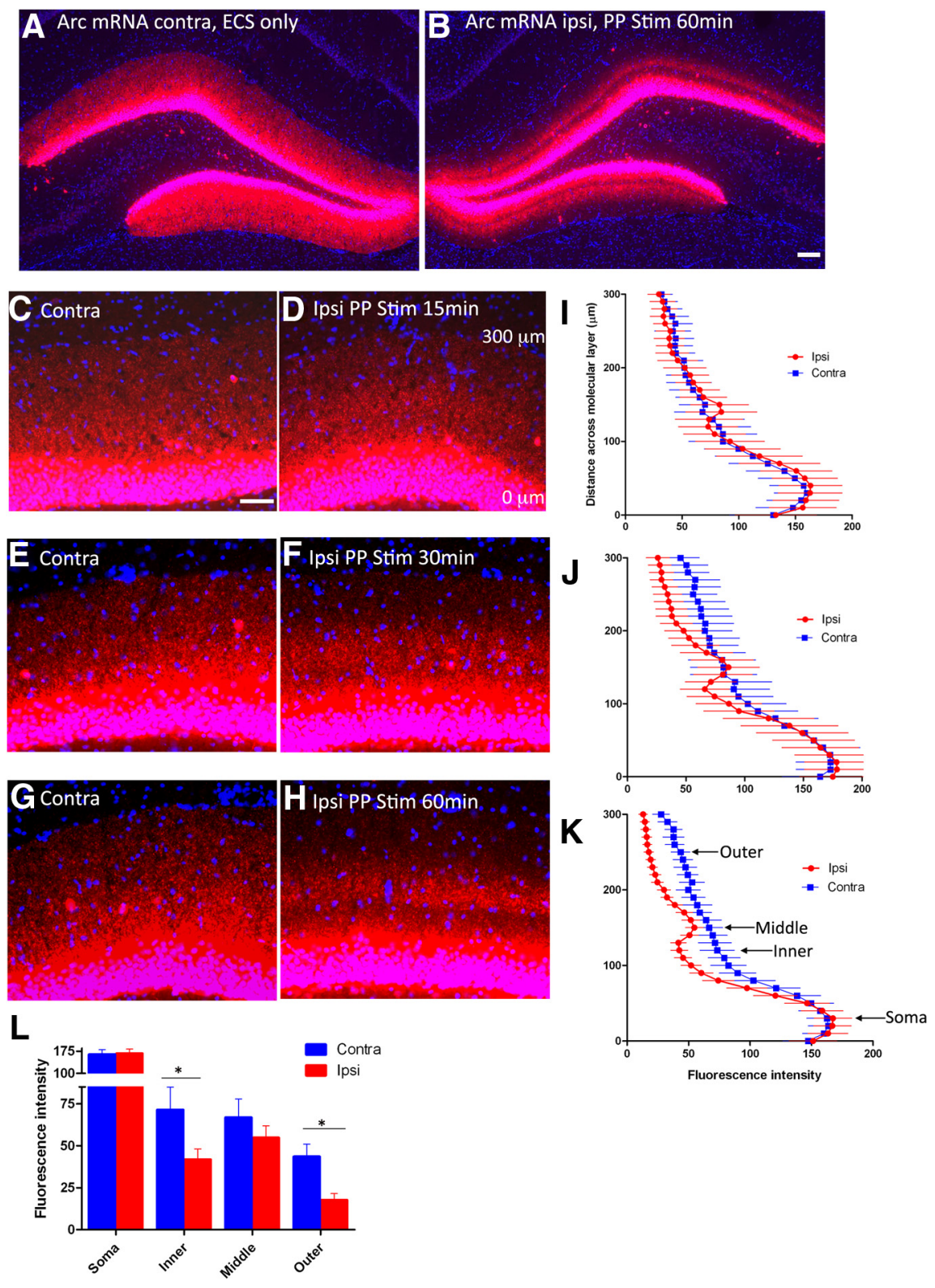

Figure 2. Synaptic activity causes depletion of Arc mRNA in non-activated dendritic domains. $A, B$, Representative FISH images labeled for Arc mRNA (red) and nuclei (blue) on a rat that received ECS and PP stimulation for $60 \mathrm{~min}$. $\boldsymbol{A}$, Contralateral ECS-only control. $\boldsymbol{B}$, Ipsilateral PP stimulation. $\boldsymbol{C}-\boldsymbol{H}$, High-magnification FISH images of rats that received ECS and PP stimulation for 15,30 , and $60 \mathrm{~min} . \boldsymbol{I}-\boldsymbol{K}$, Quantification of fluorescence intensity across the cell body $(0 \mu \mathrm{m})$ to the end of the molecular layer $(300 \mu \mathrm{m})$ in $\boldsymbol{C} \boldsymbol{H}(n=4-6$ rats each; see Results). $\boldsymbol{L}$, Statistical assessment from four measuring sites (denoted by arrows in $\boldsymbol{K}$ ) from the 60 $\min$ PP stimulation quantification (Wilcoxon's signed-rank test, ${ }^{*} p<0.025$ and 0.001 for inner and outer regions, respectively; $n=6$ rats). Contra, Contralateral; Ipsi, ipsilateral. Scale bars: $\boldsymbol{B}, 100 \mu \mathrm{m} ; \boldsymbol{C}, 50 \mu \mathrm{m}$.

at active synapses is primarily attributable to the disappearance of Arc mRNA from the inactive laminae.

\section{Arc mRNA that accumulates at activated synapses is newly synthesized}

One possible explanation for the depletion of Arc mRNA from inactive laminae is that Arc mRNA that was already in dendrites relocalized to the activated lamina. However, another possibility is that the Arc mRNA that localizes at activated synapses is newly transcribed at the same time that $A r c$ mRNA in the non-activated laminae is degraded. To test whether the Arc mRNA that accumulates at activated synapses is newly synthesized, we locally delivered the transcription inhibitor ActD into the dentate gyrus 


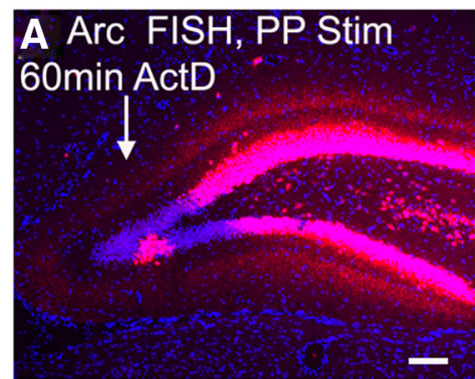

E

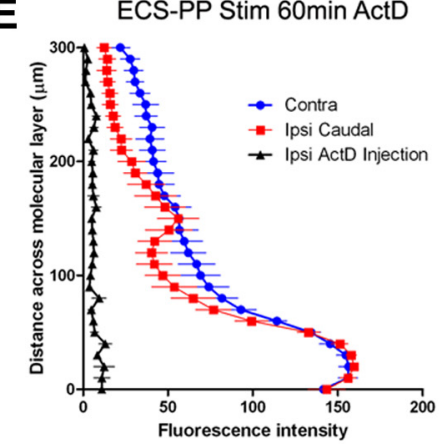

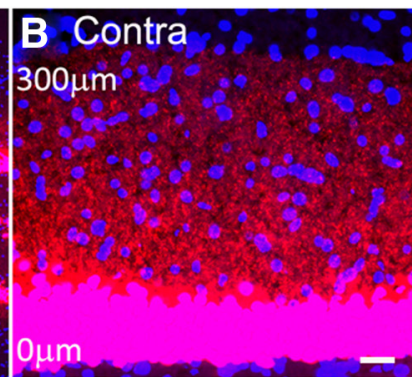

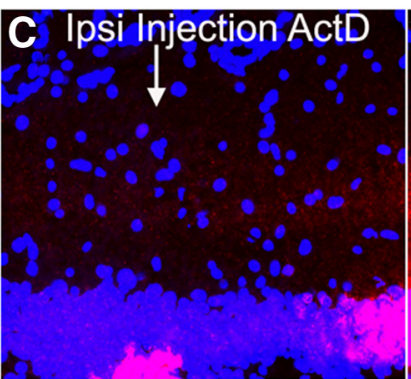

$\mathbf{F}$

ECS-PP Stim 60min ActD

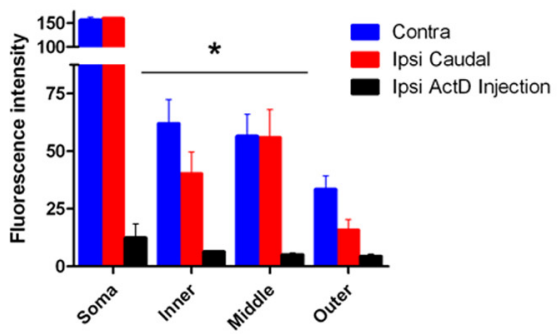

$\mathbf{F}$

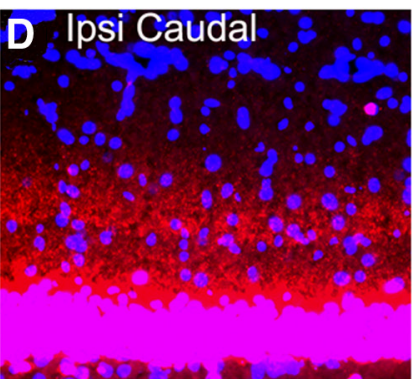

G

ECS only ActD
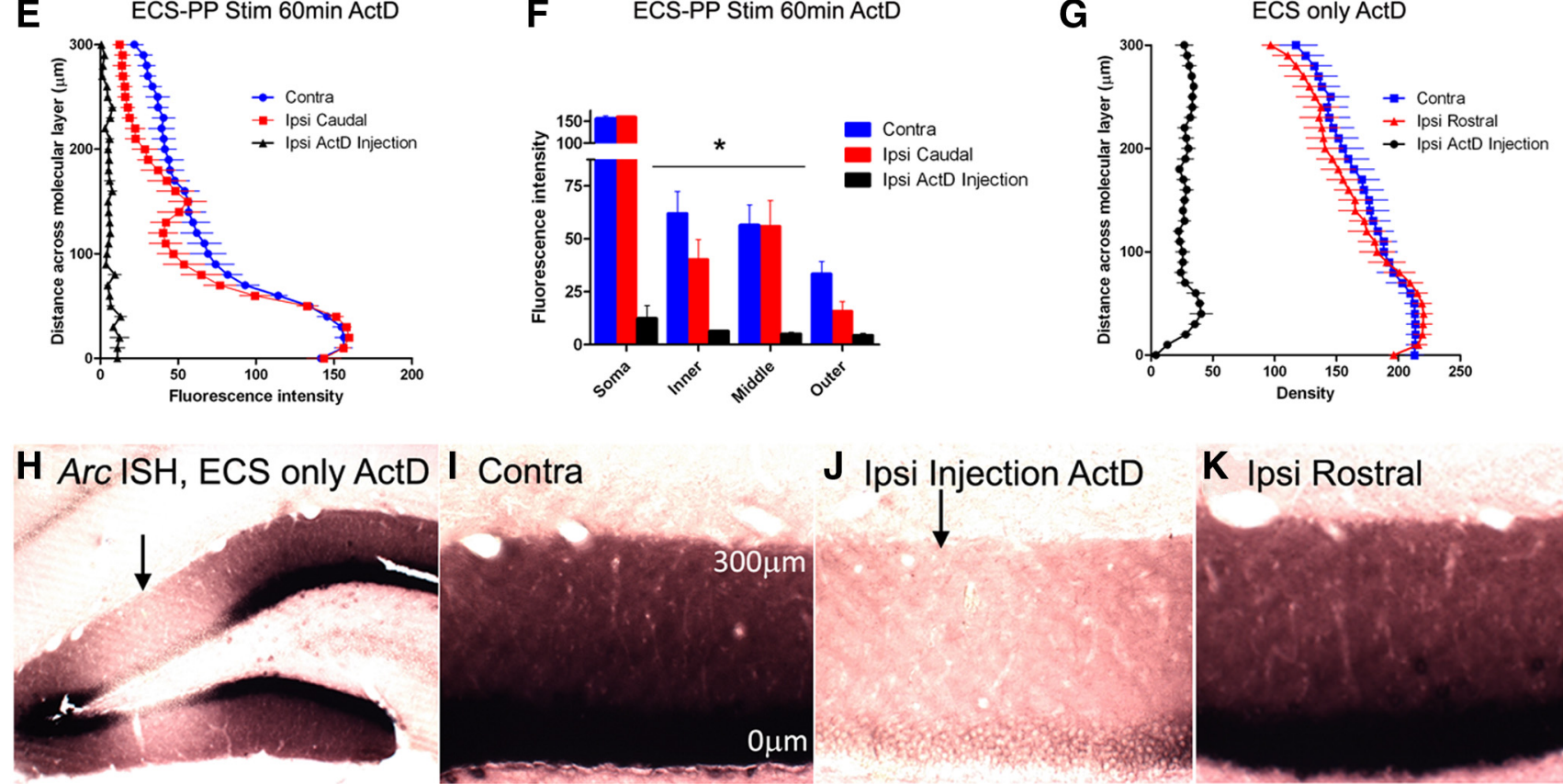

I Contra

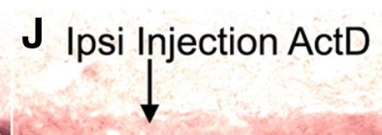

K Ipsi Rostral
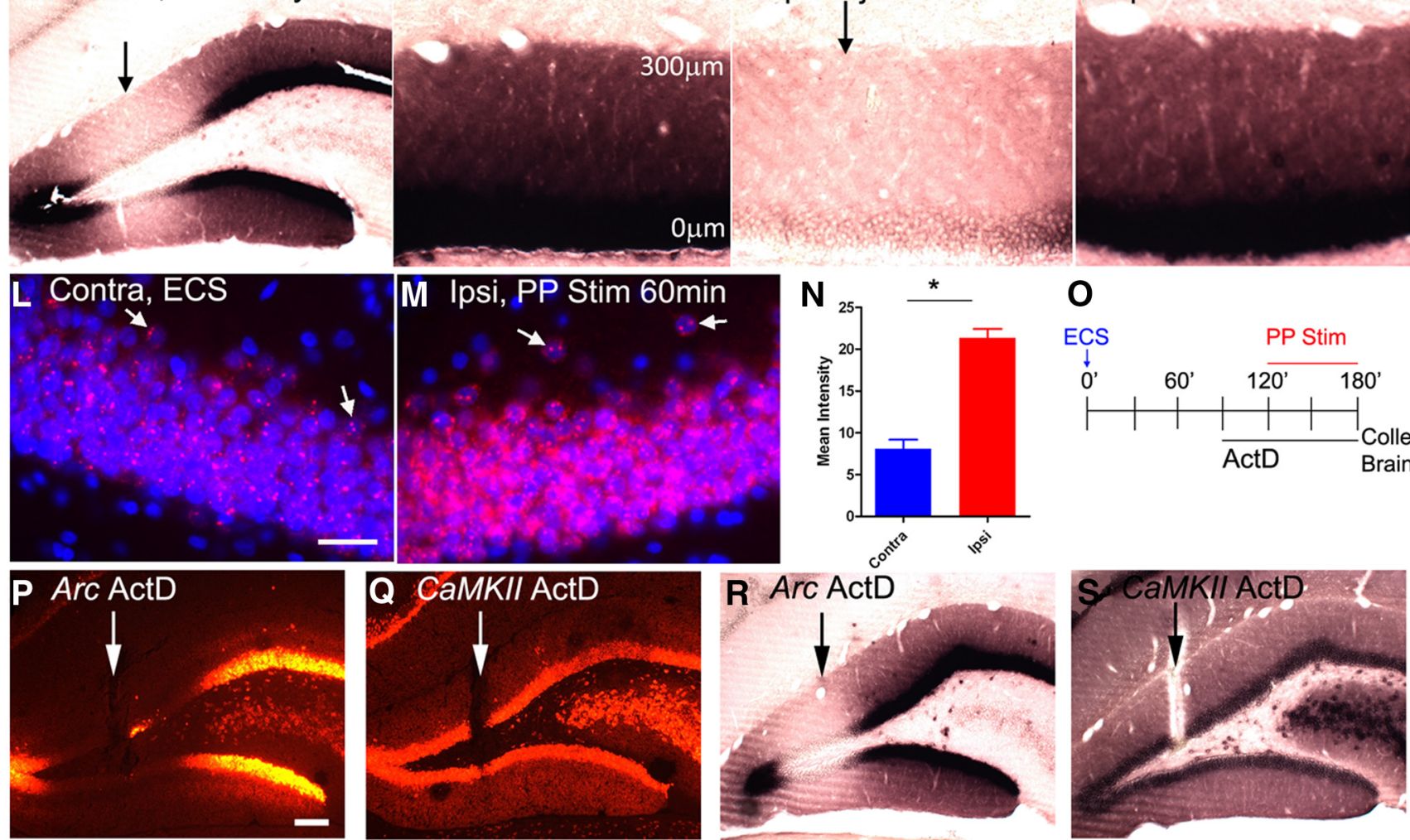

Figure 3. Arc mRNA accumulation in the zone of activated synapses is dependent on de novo Arc transcription and transport. $A-D$, Representative FISH images labeled for Arc mRNA (red) and nuclei (blue) on a rat that received ECS and PP stimulation for $60 \mathrm{~min}$ with ActD infusion. $A$, Ipsilateral PP stimulation at an ActD injection site (arrows denote ActD electrode path). $\boldsymbol{B}$, Contralateral ECS-only side. C, ActD injection site (white arrow). $\boldsymbol{D}$, A section caudal to the ActD injection. $\boldsymbol{E}, \boldsymbol{F}$, Quantification of average fluorescence intensity $\left(n=3\right.$, two-way paired ANOVA, ${ }^{*} p<0.001$ for Ipsi vs Injection Soma and Middle, ${ }^{*} p<0.05$ for Ipsi vs Injection Inner; Ipsi vs Injection Outer, n.s.). G, Quantification of average density in ECS-only ActD rats $(n=3$ rats). $\boldsymbol{H}-\boldsymbol{K}$, Representative ISH images labeled for Arc mRNA on a rat that received ECS only with ActD infusion. $\boldsymbol{H}$, Ipsilateral ECS side at the ActD injection site. I, Contralateral ECS-only side. J, ActD injection site. $\boldsymbol{K}$, A section caudal to the ActD injection. $L, M$, Representative Arc FISH images labeled with the Arc intron-specific probe on a rat that received ECS-PP stimulation. White arrows indicate examples of granule cells with Arc transcription foci. $\boldsymbol{N}$, Mean fluorescence intensity of the Arc intron probe on granule cell body layers (paired Student's test, ${ }^{*} p<0.0001 ; n=3$ rats). $\mathbf{O}$, Schematic of ActD experiments. $\boldsymbol{P}, \boldsymbol{Q}$, Adjacent electrode track sections from a rat that received local infusion of ActD and processed for Arc and $\alpha$ CaMKII FISH, respectively. Note the depletion of Arc FISH signal around the ActD electrode (white arrow) in $\boldsymbol{P}$ and the lack of effect with $\alpha$ CaMKII FISH in $\mathbf{Q}$. $\boldsymbol{R}, \mathbf{S}$, Similar results as in $\boldsymbol{P}$ and $\mathbf{Q}$ but with adjacent electrode track sections processed for ISH. Contra, Contralateral; Ipsi, ipsilateral. Scale bars: $A, P, 100 \mu \mathrm{m} ; \boldsymbol{B}, L, 25 \mu \mathrm{m}$. 
after Arc was diffusely distributed in dendrites (from ECS) but before PP stimulation (see schematic in Fig. 3O). For these and subsequent experiments involving drug application, we used an approach developed previously (Steward et al., 1998; Steward and Worley, 2001) in which drugs are delivered via diffusion from micropipette recording electrodes stereotaxically repositioned in the dentate gyrus in place of the saline-filled micropipette recording electrodes. The drugs passively diffuse from the micropipette for $30 \mathrm{~min}$ while recording baseline responses. This method of local drug delivery creates an area of blockade ranging from $\sim 0.5 \mathrm{~mm}$ to several millimeters in diameter depending on the properties of the drug.

For experiments involving ActD, rats received an ECS and were then anesthetized and prepared for acute neurophysiology. A stimulating electrode was positioned in the entorhinal cortex to activate the PP, and a saline-filled micropipette recording electrode was positioned in the dentate gyrus to monitor evoked responses. Baseline responses were collected ( $0.1 \mathrm{~s}$ intervals) until $1.5 \mathrm{~h}$ after ECS (when Arc is diffusely distributed throughout granule cell dendrites), and then the saline electrode was stereotaxically replaced with a micropipette filled with ActD ( $2 \mathrm{mg} / \mathrm{ml}$ dissolved in saline). Test responses were collected for $30 \mathrm{~min}$ as ActD passively diffused from the electrode; there was no significant change in response amplitude over the $30 \mathrm{~min}$ interval. PP stimulation was then delivered for $60 \mathrm{~min}$, and the tissue was processed for FISH.

As documented in Figure 3, blockade of transcription with ActD led to a nearly complete depletion of Arc mRNA in both cell bodies and dendrites across a $0.5 \mathrm{~mm}$ region. Figure $3 A$ illustrates the ActD site and surrounding region in which Arc mRNA levels were near baseline in a region $\sim 0.5 \mathrm{~mm}$ in diameter around the ActD site. The depletion of Arc mRNA seen here cannot be attributed to damage from the micropipette, because in numerous previous experiments in which the recording micropipettes contain only saline, there is no depletion of Arc mRNA at the site of recording (see examples by Steward et al., 1998). In addition, when sections adjacent to the one shown in Figure $3 \mathrm{~A}$ were hybridized for $\alpha C a M K I I$ mRNA, there was no evidence of depletion at the recording site (see examples in Fig. $3 P-S$ ). Thus, the depletion of $A r c$ mRNA reflects blockade of ongoing transcription.

For quantitative analyses, we assessed fluorescence intensity across the cell body and dendritic layers on the ECS-only side (Fig. 3B), in the center of the ActD site (Fig. 3C), and in regions distant from the ActD site (Fig. 3D). Quantification of average fluorescence intensity averaged across three rats is illustrated in Figure 3, E and F. Arc mRNA levels were significantly decreased within the cell bodies and dendrites in the region of transcriptional blockade compared with the levels outside of ActD diffusion ( $n=3$; two-way paired ANOVA, $p<0.001)$. These results indicate the following: (1) the maintenance of high Arc mRNA levels during PP stimulation de- pends on continuing transcription; and (2) it is mainly newly transcribed Arc mRNA that localizes at activated synapses. Thus, the disappearance of Arc mRNA from inactive domains must reflect mRNA degradation.

Because maintenance of high levels of Arc mRNA during PP stimulation depends on continuing transcription, we wondered whether the high levels of Arc mRNA on the ECS-only side also depended on ongoing transcription. To test this, ActD was delivered $1.5 \mathrm{~h}$ after ECS as described above, and rats were killed $1.5 \mathrm{~h}$ later without delivering PP stimulation. Figure $3 \mathrm{H}$ illustrates the ActD site and surrounding region in one experiment in which Arc mRNA levels were near baseline in a region $\sim 0.5 \mathrm{~mm}$ in diameter around the ActD site. In Figure 3, I illustrates Arc mRNA levels on the contralateral side, $J$ illustrates the center of the ActD site and $K$ illustrates a region distant from the ActD site. The average optical density across the cell body and dendritic layers averaged across three rats is illustrated in Figure 3G. Thus, maintenance of high levels of Arc mRNA for hours after a single ECS (Wallace et al., 1998) depends on continuing transcription.

PP stimulation strongly induces Arc transcription from the basal state, but it is conceivable that such activity might downregulate ongoing transcription after a seizure, which could account for the lower levels of Arc mRNA on the stimulated side. To test this, we measured $A r c$ transcription using a probe directed to the intronic sequence in $\operatorname{Arc}$ mRNA that is spliced out in the nucleus. With this probe, only pre-spliced Arc mRNA is detected, so that labeling appears as two distinct spots representing transcription foci in the nucleus of activated cells (Guzowski et al., 


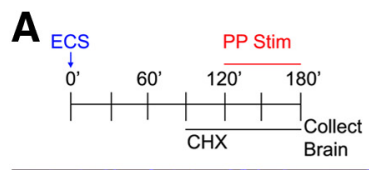

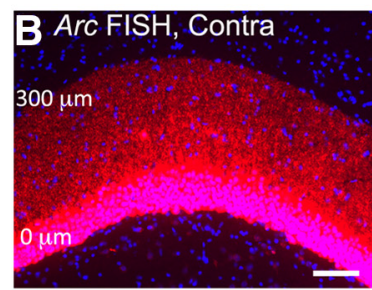
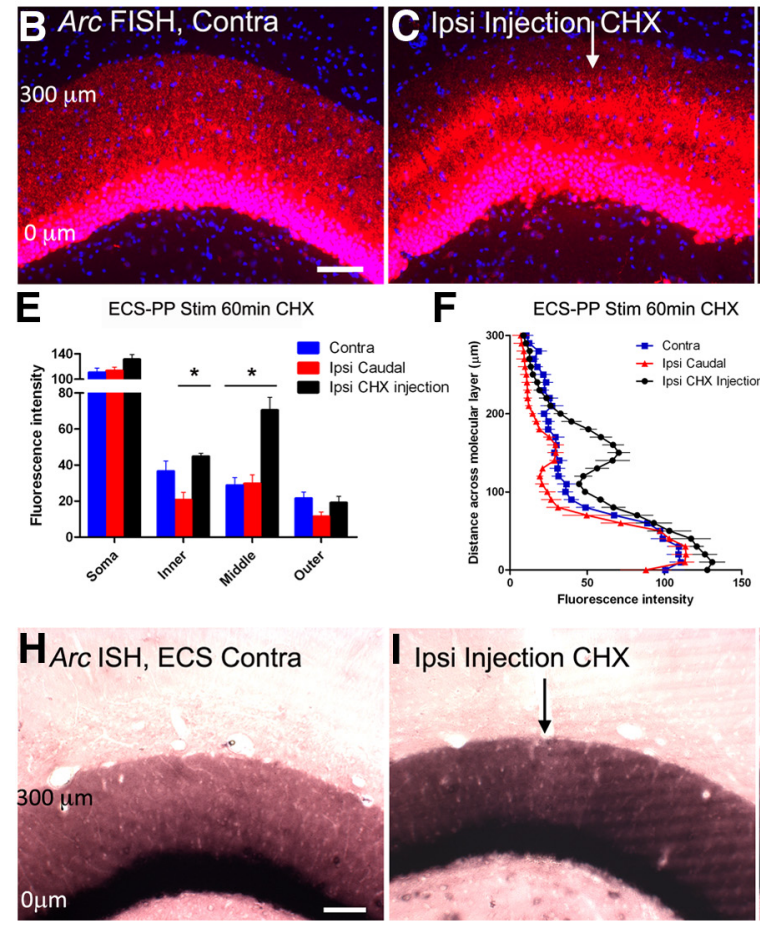

F ECS-PP Stim 60min CHX
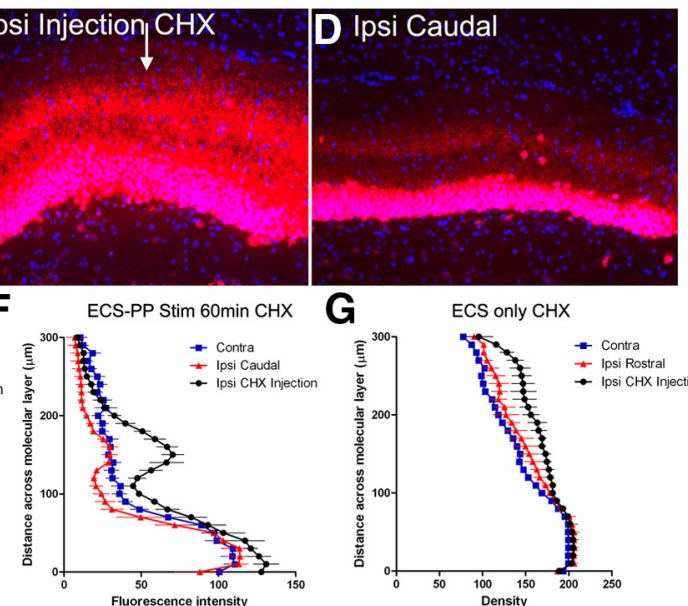

G

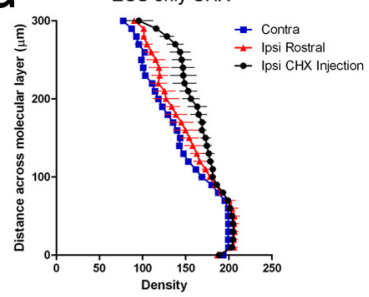

$J_{\text {Ipsi Rostral }}$

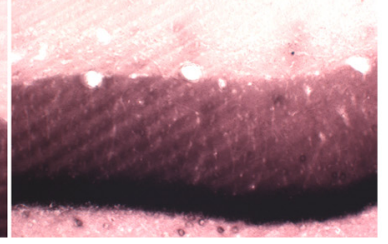

Figure 5. Arc mRNA degradation is activity and translation dependent. $\boldsymbol{A}$, Schematic of CHX experiment. $\boldsymbol{B}-\boldsymbol{D}$, Representative FISH images labeled for Arc mRNA (red) and nuclei (blue) on a rat that received ECS and PP stimulation for 60 min with CHX infusion. $\boldsymbol{B}$, Contralateral ECS-only control side. C, Ipsilateral PP stimulation side at CHX injection site (arrows denote CHX electrode path). D, Ipsilateral PP stimulation caudal to the CHX injection site. Note that exposures times were set to be able to detect dendritic mRNA in sections caudal to the CHX site. Consequently, the injection site image in $\boldsymbol{D}$ is overexposed. $\boldsymbol{E}, \boldsymbol{F}$, Quantification of average fluorescence intensity (two-way paired ANOVA, ${ }^{*} p<0.0001 ; n=3$ ). G, Quantification of Arc mRNA on rats that received ECS only and CHX infusion $(n=2)$. $\boldsymbol{H}-\boldsymbol{J}$, Representative Arc ISH images from the quantification seen in $\mathbf{G}$. Contra, Contralateral; Ipsi, ipsilateral. Scale bar: $\boldsymbol{B}, \boldsymbol{H}, 50 \mu \mathrm{m}$.

2006). Figure 3, $L$ and $M$, illustrates high-magnification views of the granule cell layer on the ECS-only side and on the PP stimulated side in one experiment. Quantitative analyses from three rats revealed 2.6-fold higher levels of labeling intensity with the intron probe on the stimulated side (Fig. $3 N$ ). These results suggest that levels of transcription are actually considerably higher with PP stimulation, although the overall level of Arc mRNA in the activated dendrites is lower. One alternative possibility is that the decrease in Arc mRNA on the stimulated side, despite increases in pre-spliced mRNA, is attributable to decreased efficiency in splicing and export. To exclude this possibility, we also assessed Arc mRNA expression in granule cell somata using a different $A r c$ probe against the $3^{\prime}$ end of the transcript, which detects total Arc mRNA. Again, labeling with this probe was higher in granule cell somata on the stimulated side (data not shown). Together, these findings are compelling evidence that decreases in levels of Arc mRNA in dendrites on the stimulated side are not a result of decreased transcription and instead reflect activity-driven mRNA degradation.

\section{Activity-driven depletion of Arc mRNA fluorescence is attributable to decreases in particle number}

The depletion of Arc mRNA in the inactive dendritic domains, revealed by decreases in fluorescence intensity, could reflect either decreases in the number of Arc mRNA particles or decreases in the size of individual particles. Decreases in the size of individual particles would imply that each particle contains multiple copies of Arc mRNA, so that particle size would decrease in a stepwise manner as individual mRNAs are degraded. Decreases in particle number would imply that there are relatively few copies of Arc mRNA per particle or that all copies in a given particle were degraded more or less simultaneously.

To assess particle number and size during activity-dependent mRNA depletion, images were captured at $63 \times$ magnification from the stimulated and control (ECS-only) sides from one rat after 60 min of PP stimulation. The apparent size (diameter) and number of individual Arc mRNA particles, visualized with FISH, throughout the dendritic laminae were measured across three sections. Particle size ranged from 0.3 to $1.8 \mu \mathrm{m}$ in diameter across the dendritic laminae, with an average of $\sim 0.5 \mu \mathrm{m}$. There were no differences in particle size between activated (middle lamina) and non-activated (inner and outer laminae) regions on the stimulated side and no differences in particle size between the stimulated side and the contralateral (ECS-only) control (Fig. $4 A$ ). Counts of $A r c$ mRNA particles in the different dendritic laminae revealed significant decreases in average particle number in the non-activated distal dendritic domain on the stimulated side versus the contralateral side (ECS-only) (Fig. $4 B)$. There were no significant differences in particle number in the middle or proximal dendritic laminae. Thus, activity-induced decreases in Arc fluorescence are attributable to decreases in particle number, with particle size staying constant.

\section{Arc mRNA depletion requires NMDAR activation}

We showed previously that targeting of $\operatorname{Arc}$ mRNA to active synapses requires NMDAR activation (Steward and Worley, 2001). To determine whether the depletion of $\operatorname{Arc}$ mRNA is also NMDAR dependent, micropipette recording electrodes containing the NMDAR antagonist MK-801 were positioned in the dentate gyrus $1.5 \mathrm{~h}$ after ECS and $30 \mathrm{~min}$ before PP stimulation (see schematic in Fig. 4C). When delivered in this way, MK-801 blocks NMDAR activation in a region $\sim 1 \mathrm{~mm}$ in diameter (Steward and Worley, 2001). Arc mRNA levels were assessed after $1 \mathrm{~h}$ of $\mathrm{PP}$ stimulation by non-isotopic colorimetric ISH. In Figure $4, D$ and $F$ illustrate the labeling pattern on the ECS-only side, $E$ and $G$ illustrate the MK-801 site and surrounding region, and $H$ illustrates a region distant from the $\mathrm{MK}-801$ site. In the presence of MK-801, Arc mRNA did not accumulate in the activated lamina, and there was no depletion of $A r c$ mRNA in the inactive dendritic laminae (outer and inner molecular layers). In other words, the net level of Arc mRNA remained identical to the ECS-only control side. Quantitative analysis of optical density across the molecular layer averaged from three rats (Fig. 4I) revealed that Arc mRNA levels in the area of MK-801 blockade were virtually iden- 
tical to the contralateral ECS-only control, whereas the expected banding pattern and overall decreases in mRNA levels were seen in areas distant from the MK-801 site. The bar graph in Figure $4 J$ directly compares the average Arc mRNA levels ( $n=3$ rats) in the different domains. We know from our results above that there are ongoing levels of transcription on the ESC-only control side, but because there is no net change in Arc mRNA levels, the rate of transcription equals the rate of degradation (steady state). For there to be a net decrease in Arc mRNA under stimulating conditions, NMDAR activation must increase the rate of Arc degradation because it increases the rate of Arc transcription. Thus, in addition to inducing Arc transcription and localization, NMDAR activation also drives Arc mRNA degradation.

\section{Arc mRNA degradation depends on active translation}

Previous studies showed that Arc mRNA is a target for nonsensemediated decay (NMD) because of the presence of introns positioned in its 3'UTR (Giorgi et al., 2007). A key feature of NMD is that it is triggered by interactions between a terminating ribosome and downstream NMD factors recruited to the target mRNA. When translation is inhibited, ribosomes are unable to trigger NMD, and, therefore, NMD targets are stabilized. To assess whether activity-dependent degradation of Arc mRNA is dependent on mRNA translation, micropipette recording electrodes containing the protein synthesis inhibitor CHX were positioned in the dentate gyrus $1.5 \mathrm{~h}$ after ECS and $30 \mathrm{~min}$ before PP stimulation (see schematic in Fig. $5 A$ ). When delivered in this way, CHX completely blocks protein synthesis in a region $\sim 1$ $\mathrm{mm}$ in diameter (Steward et al., 1998). Figure 5B-D illustrates the results seen in one rat, and quantitative analyses averaged across three rats are illustrated in Figure 5E. Compared with the ECSonly side (Fig. 5B), $A r c$ mRNA levels were higher in the area of CHX diffusion (Fig. 5C). The depletion of Arc mRNA that was otherwise seen outside the area of CHX (Fig. 5D) was completely blocked in the CHX site. Quantitative analyses revealed that Arc mRNA levels were higher throughout the cell body and dendritic lamina in the area of protein synthesis blockade (Fig. 5E). Similar results were seen but not quantified in a previous study with local delivery of puromycin (Steward et al., 1998).

Plots of average fluorescence intensity across the cell body and molecular layer in three rats (Fig. $5 F$ ) revealed a surprising fact: although Arc mRNA levels were higher throughout cell bodies and dendrites in the area of protein synthesis blockade, the difference was greatest in the activated lamina. When comparing the area of protein synthesis blockade with distant caudal regions outside of the CHX blockade on the stimulated side, the greatest difference in levels is exactly in the region of the activated synapses. This means that Arc mRNA degradation is occurring primarily in regions in which Arc mRNA accumulates and is most actively translated.

Given the above, it was of interest to assess the consequences of blocking protein synthesis after ECS only, when there is ongoing Arc transcription but no imposed synaptic activity. To assess this, micropipette recording electrodes containing CHX were po- sitioned in the dentate gyrus $1.5 \mathrm{~h}$ after an ECS as above, but the rats received no PP stimulation. After 90 min of protein synthesis blockade, Arc mRNA levels were slightly higher in the area of CHX blockade (Fig. 5I) compared with the contralateral ECSonly side (Fig. $5 H$ ) or areas distant from the CHX site (Fig. $5 J$ ). Quantitative analyses averaged across two rats revealed that levels of $A r c$ mRNA were 20\% higher across the dendritic lamina (Fig. $5 G)$. Thus, there is some translation-dependent mRNA decay in the absence of synaptic activity, but the decay occurs throughout the dendritic lamina rather than in a particular dendritic domain as is the case with synaptic stimulation.

\section{ARC protein localization mirrors the localization of Arc mRNA}

As shown in previous studies, ECS alone strongly induces ARC protein expression, as evidenced by increased immunostaining in granule cell bodies and uniformly high levels of protein throughout the dendritic laminae (Fig. 6, compare $A, B$ ). With subsequent delivery of $1 \mathrm{~h}$ of PP stimulation (as above), a band of increased immunostaining for ARC protein appears in the activated lamina (the same zone in which $\operatorname{Arc}$ mRNA accumulates; Fig. 6C). Quantitative assessment of fluorescence across the cell body and molecular layers averaged from three rats reveals that the distinctness of the protein band is attributable to decreases in levels of ARC protein in the non-activated inner and outer dendritic zones (Fig. 6F). Decreases in ARC protein in the nonactivated laminae could be directly attributable to the activityinduced decrease in levels of Arc mRNA, to activity-induced ARC protein degradation in the non-activated laminae, or to a combination of both.

If decreased levels of ARC protein after PP stimulation are attributable to activity-induced ARC protein degradation, then blocking new protein synthesis after ARC protein levels are high (after ECS) but before PP stimulation should lead to rapid decreases in ARC protein. In addition, if differential ARC protein distribution in the activated lamina versus non-activated laminae requires translation of the newly synthesized, differentially localized mRNA, blocking protein synthesis should also prevent the development of a band of increased protein in the activated lamina. To assess this, we immunostained sections from cases above 

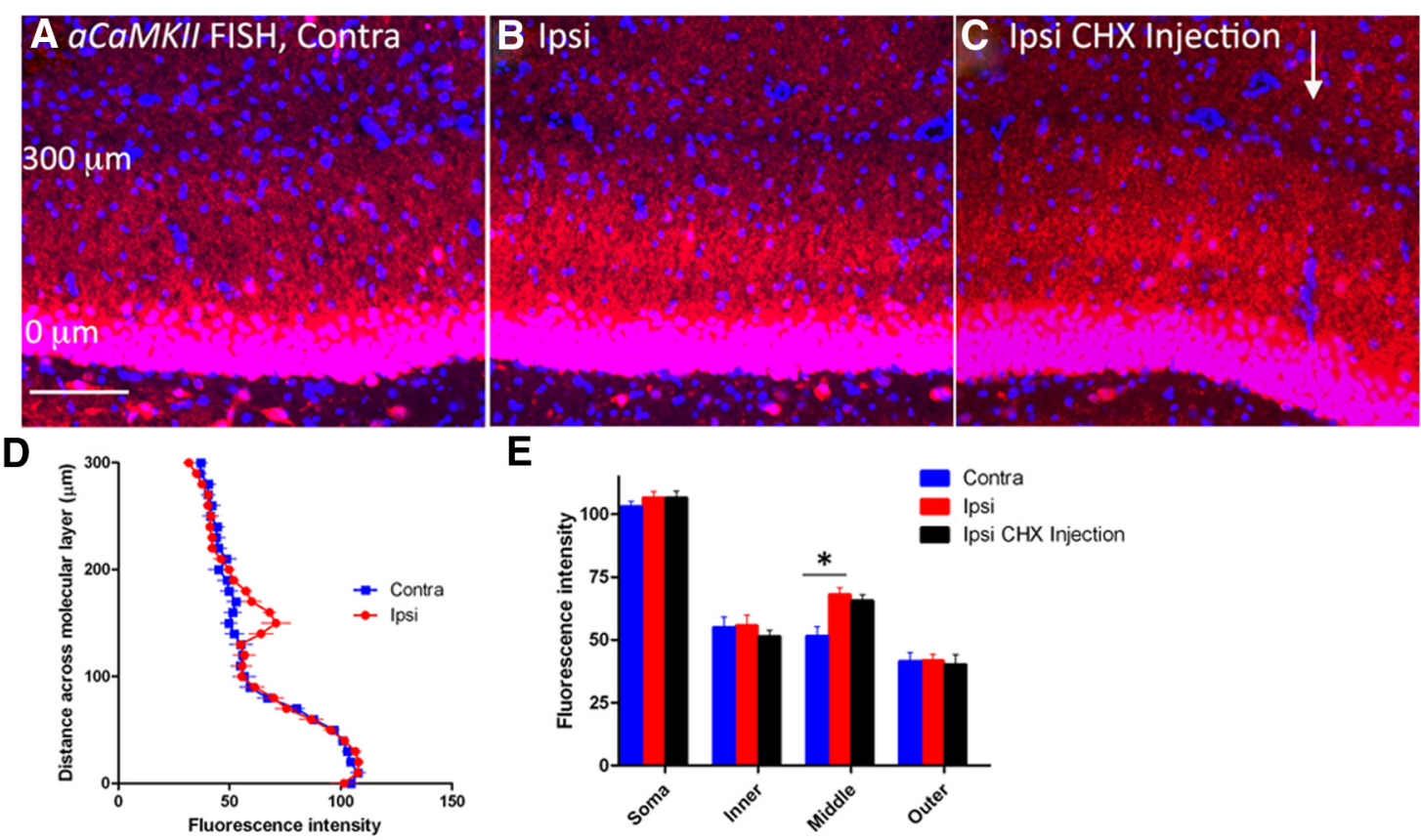

Figure 7. Activity induces $\alpha$ CaMKII mRNA localization to activated synapses but not depletion in non-activated regions. A-C, Representative FISH images labeled for $\alpha$ CaMKII mRNA (red) and nuclei (blue) on rats that received ECS-PP stimulation for 60 min with either saline or CHX infusion. $\boldsymbol{A}$, Contralateral ECS-only control side. $\boldsymbol{B}$, Ipsilateral PP stimulation side. C, Ipsilateral PP stimulation side at CHX injection site (arrows denote electrode path). $\boldsymbol{D}$, Quantification of $\boldsymbol{A}$ and $\boldsymbol{B}$ ( $n=6$ rats). $\boldsymbol{E}$, Quantification of $\boldsymbol{A}-\boldsymbol{C}\left(n=3\right.$ rats for $\mathrm{CHX} ;{ }^{*} p<0.01$, Middle Ipsi vs Contra). Scale bar, $150 \mu \mathrm{m}$.

in which $\mathrm{CHX}$ was locally infused through a recording pipette $1.5 \mathrm{~h}$ after ECS when ARC protein levels are high and just before the onset of PP stimulation and then delivered PP stimulation for 60 min. Remarkably, ARC protein levels decreased over the period of PP stimulation to near basal levels in the area of CHX blockade (Fig. 6D). Quantitative assessment of fluorescence averaged from three rats revealed complete loss of ARC protein in the area of CHX blockade, whereas outside the area of blockade, a band of increased ARC protein developed as expected (Fig. $6 F$ ). It is important to note that low doses of CHX have been reported to increase the translation of certain mRNAs, such as Arc, likely through cap-independent mechanisms involving internal ribosomal entry site sequences (Park et al., 2008). However, the doses used in the present study are sufficiently high enough to block Arc translation as shown clearly in Figure 6D.

Thus, maintenance of high levels of ARC protein overall and the development of the band of increased ARC protein in the activated lamina depend on ongoing protein synthesis. The dependence on continual translation and the close correspondence between the localization of $A r c$ mRNA and protein strongly suggest that the distribution of ARC protein at any point in time is determined by the distribution of and local translation of Arc mRNA.

\section{$\alpha C a M K I I$ mRNA is not subject to activity- or} translation-dependent mRNA degradation

One important question is whether activity-dependent mRNA degradation is exclusive to $A r c$ or whether other dendritic mRNAs are degraded in the same manner. Using sections from the experiments described above, we assessed the distribution of the mRNA for $\alpha$ CaMKII by FISH. Comparisons of labeling on the ECS-only side (Fig. 7A) with the side that received PP stimulation (Fig. $7 B$ ) revealed no depletion of $\alpha C a M K I I$ mRNA as a result of synaptic activation. Surprisingly, however, PP stimulation did cause $\alpha C a M K I I$ mRNA to accumulate in the activated dendritic lamina (Fig. 7B). Quantitative assessment of fluorescence across the cell body and dendritic layers averaged from six rats confirmed that there was no decrease in levels of $\alpha$ CaMKII mRNA in the inactivated laminae, whereas $\alpha$ CaMKII mRNA levels were significantly higher in the activated region than the adjacent non-activated regions and the contralateral ECS-only side (Fig. $7 D, E$ ). Using adjacent sections from the same ECS-PP stimulation with $\mathrm{CHX}$ infusion cases described above, we also assessed whether local blockade of protein synthesis led to increases in $\alpha$ CaMKII mRNA. Figure 7C illustrates the pattern of labeling in the area of the CHX injection (the track of the micropipette is evident). Quantitative analyses revealed that there were no differences in the pattern of labeling between rats that received $\mathrm{CHX}$ during PP stimulation ( $n=3$ rats) and PP stimulation saline vehicle controls ( $n=6$ rats).

\section{Arc and CAMKII mRNAs are in separate particles}

Because both $A r c$ and $\alpha C a M K I I$ mRNAs accumulate at activated synapses, the question arose whether the two transcripts were in the same or different particles. Subcellular fractionation studies provided evidence that these two mRNAs are packaged in the same type of ribonuclear particle (Kanai et al., 2004; Gao et al., 2008). Arc and $\alpha$ CaMKII mRNA both have A2 response elements, a cis-acting signal for RNA trafficking, and have been shown to bind its trans-acting factor, heterogeneous nuclear ribonucleoprotein A2, in neurons (Shan et al., 2003; Gao et al., 2008). However, this does not exclude the possibility that each mRNA may be in biochemically similar but separate particles in vivo.

To determine the degree of colocalization, sections from one rat that had been stimulated for $2 \mathrm{~h}$ to cause maximal accumulation at activated synapses were prepared for double-labeled FISH. For this, we used RNAscope probes (Advanced Cell Diagnostics), which was essential for the critical control experiment described below. Cohybridization with probes for Arc and $\alpha C a M K I I \mathrm{mR}$ - 
NAs revealed very little if any colocalization in either granule cell bodies (Fig. $8 A, G$ ) or in the dendritic laminae (Fig. $8 B, H)$. Quantitative analyses of particle number over the dendritic laminae revealed that $\alpha$ CaMKII mRNA particles were approximately five times more abundant than Arc mRNA particles in both the activated (middle dendrites) and the non-activated inner dendritic lamina (Fig. 8C). Only $\sim 7-8 \%$ of the Arc mRNA particles were colocalized with $\alpha C a M K I I$ mRNA particles (Fig. 8C). Virtually identical results, that is minimal $\alpha C a M K I I$ and Arc mRNA particle colocalization, were seen using traditional doublelabeled FISH methods (data not shown).

An important control is to show that two probes against the same mRNA lead to double labeling of particles. To test this, we generated two RNAscope probes against non-overlapping regions of the Arc transcript: one to the $5^{\prime}$ end and the other to the $3^{\prime}$ end of Arc mRNA. Cohybridization with these two probes led to colabeling of a substantial number of particles in both the cell bodies (Fig. 8D,I) and dendritic laminae (Fig. $8 E, J$ ). Thus, colocalization is easily detectable when present. Nevertheless, quantitative analysis revealed that colocalization of the two Arc probes was not $100 \%$ (Fig. $8 F$ ). This is likely attributable to stearic hindrance of the two Arc RNAscope probes because, when the probes were hybridized individually, a larger number of particles were detected than when the two probes were hybridized together (data not shown).
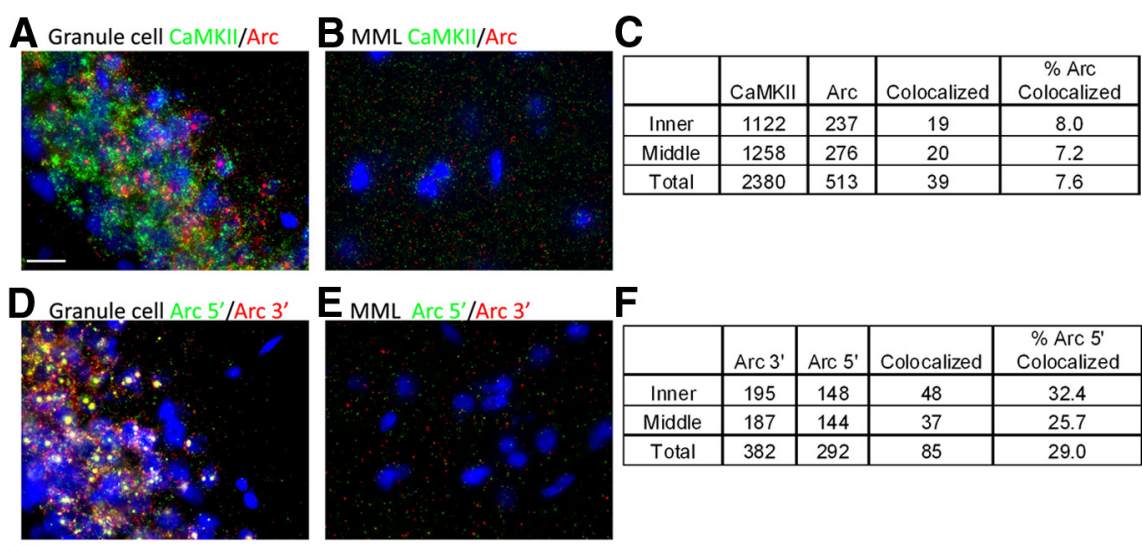

$\mathbf{F}$
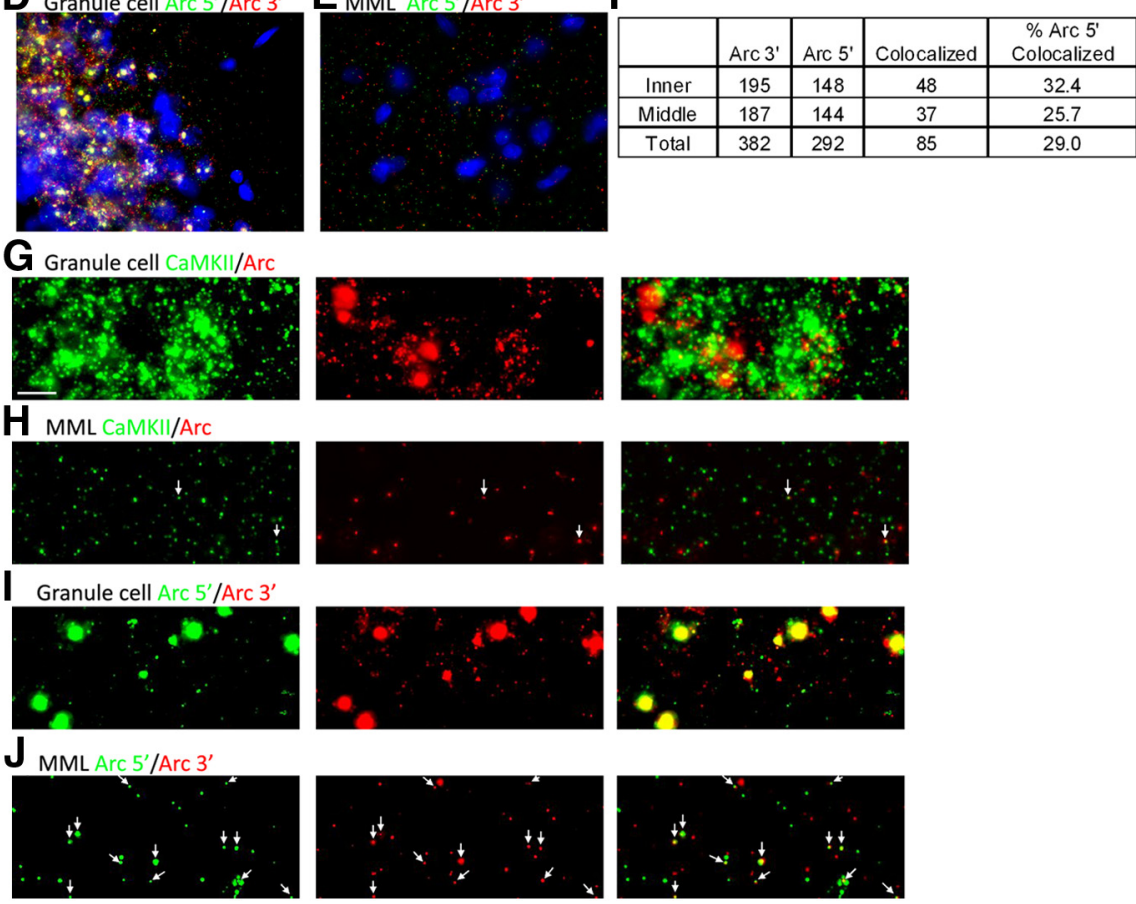

Figure 8. Arc and $\alpha$ CaMKII mRNA particles are distinct in dentate granule cell dendrites in vivo. $\boldsymbol{A}, \boldsymbol{B}$, Double-labeled FISH using RNAscope for $\alpha$ CaMKII and Arc mRNA in dentate gyrus granule cell bodies and molecular layer of a rat that received $2 \mathrm{~h} P \mathrm{PP}$ stimulation. C, Quantification of particle number and particle colocalization detected in the inner and middle molecular layers. $\boldsymbol{D}$, $\boldsymbol{E}$, Double-labeled FISH for $\operatorname{Arc} 5^{\prime}$ and $A r c 3^{\prime}$ probes in the same tissue as $\boldsymbol{A}$ and $\boldsymbol{B}$. F, Quantification of particle number and particle colocalization detected in the inner and middle molecular layers. G-J, Representative high-magnification images of granule cell bodies and molecular layers from the experiments in $\boldsymbol{A}-\boldsymbol{F}$. White arrows denote colocalized particles in dendrites. MML, middle molecular layer. Scale bars: $\boldsymbol{A}, 25 \mu \mathrm{m} ; \boldsymbol{G}, 10 \mu \mathrm{m}$.

\section{A learning experience drives protein synthesis-dependent Arc mRNA degradation}

Last, we tested whether a learning experience that induces Arc transcription would also induce translation-dependent Arc mRNA degradation in vivo. To test this, pairs of rats were allowed to explore a novel enriched environment (EE) for $15 \mathrm{~min}$ to induce $A r c$ transcription. Then one of the pair received an injection of CHX (20 mg/kg, i.p.), and the other received a vehicle injection of saline. The rats were returned to the environment to explore for an additional $60 \mathrm{~min}$ (to drive activity-induced mRNA degradation). Five different pairs of rats were treated in this way. Three other pairs of rats were taken from their home cage and given intraperitoneal injections of saline or CHX and returned to their home cage for $1 \mathrm{~h}$. At the end of the $1 \mathrm{~h}$ period, rats were rapidly anesthetized, and brains were prepared for FISH. To confirm blockade of ARC protein synthesis, sections adjacent to the ones prepared for FISH were immunostained for ARC protein. In all cases, levels of immunostaining were high in controls and uniformly low in CHX-treated rats (data not shown).

As expected, a $1 \mathrm{~h}$ experience in the EE led to dramatic increases in Arc mRNA levels in neurons throughout the hippocampus (compare labeling in home-cage saline-injected controls in Fig. $9 A$ with labeling in rats that received saline during exposure to the EE in Fig. 9C). In the EE rats, most neurons in area CA1 were strongly labeled; $~ 50 \%$ of the neurons in area CA3 were strongly labeled, and scattered neurons in the dentate gyrus were strongly labeled (Fig. 9C). Arc mRNA particles were distributed throughout the dendritic laminae in CA1-CA3 and evident in individual dendrites of dentate granule cells.

As predicted by the hypothesis for protein synthesisdependent $A r c$ mRNA degradation, Arc mRNA levels were much higher in sections from rats that received $\mathrm{CHX}$ during the EE (Fig. $9 C, D$, quantified in $I$ ). Arc labeling in CHX-treated home-cage controls was also higher than in the home-cage rats that received saline (Fig. 9A, B, quantified in $I$ ). It should be noted that the overall levels of labeling in these cage controls was higher than what is generally seen in animals that are undisturbed in their home cage. The likely explanation is that, although the animals had been handled previously, the intraperitoneal injection of either saline or CHX was a novel (and likely aversive) experience that likely triggered $A r c$ expression.

To quantify the effect of translation inhibition on $A r c$ mRNA in dendrites, Arc mRNA particles in stratum radiatum of CA1 in the above cases were imaged by deconvolution microscopy (Fig. $9 E-H)$, allowing counts of the number of particles in a defined sample area. As illustrated in Figure 9I, the number of Arc mRNA 

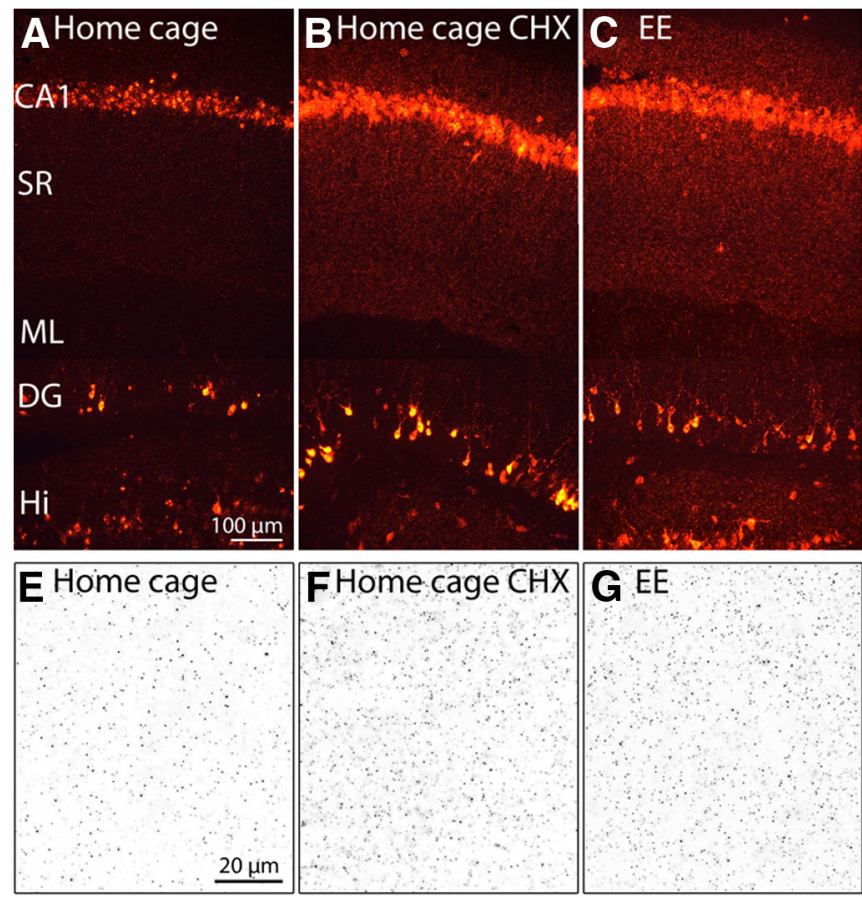

$20 \mu \mathrm{m}$

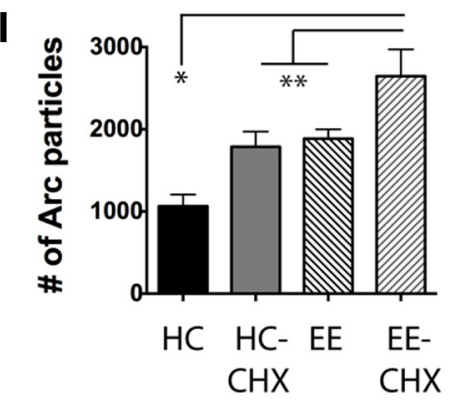

Figure 9. Unsupervised learning drives protein synthesis-dependent $\operatorname{Arc}$ mRNA degradation. $\boldsymbol{A}-\boldsymbol{D}$, Representative $\operatorname{Arc}$ FISH images of CA1 and dentate gyrus from rats that received vehicle injection of saline $(\boldsymbol{A})$ or $20 \mathrm{mg} / \mathrm{kg}$ CHX (B) and replaced in their home cages for $1 \mathrm{~h}$ or placed into an EE for $15 \mathrm{~min}$ and then received vehicle injection of saline $(\boldsymbol{C})$ or $20 \mathrm{mg} / \mathrm{kg}$ CHX (D) and replaced into the EE for 1 h. $\boldsymbol{E}-\boldsymbol{H}$, Inverted high-magnification images of Arc particles in CA1 stratum radiatum for images seen in $\boldsymbol{A}-\boldsymbol{D}$. I, Quantification of the number of Arc particles in each condition. Counts represented as mean \pm SEM [one-way ANOVA with Fisher's least significant difference test, $\alpha=0.05$; EE-CHX ( $n=5$ rats) compared with EE-saline ( $n=5$ rats), home cage-CHX ( $n=3$ rats), and home cage-saline ( $n=3$ rats); ${ }^{* *} p=0.0263,0.0293$, and ${ }^{*} p=0.007$, respectively]. DG, Dentate gyrus; HC, home cage; Hi, hilus; ML, molecular layer; SR, stratum radiatum.

particles were significantly higher in the dendritic lamina in rats that received $\mathrm{CHX}$ in the $\mathrm{EE}$ compared with rats that received saline in the $\mathrm{EE}$ and also higher than rats that received either $\mathrm{CHX}$ or saline in the home cage [one-way ANOVA with Fisher's least significant difference test, $\alpha=0.05$; EE-CHX ( $n=5$ rats) compared with EE-saline ( $n=5$ rats), home cage-CHX ( $n=3$ rats), and home cage-saline ( $n=3$ rats), $p=0.0263,0.0293$, and 0.007, respectively]. These results confirm that translation-dependent mRNA degradation occurs when Arc expression is induced in a physiological context.

\section{Discussion}

It has been known for some time that Arc mRNA localizes selectively in dendritic domains near synapses that have recently experienced strong synaptic stimulation (Steward et al., 1998). Our current results reveal several previously unknown features about this process: (1) selectivity of localization depends in part on activity- and protein synthesis-dependent mRNA degradation, which is triggered by NMDAR activation;

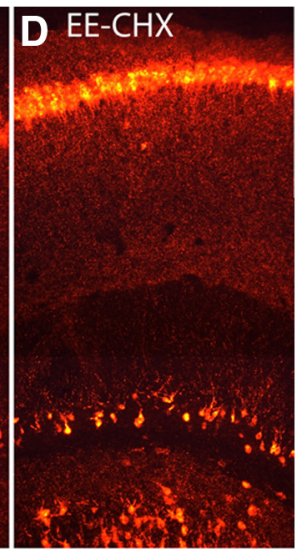

(2) Arc mRNA that accumulates at active synapses is mostly newly synthesized during the period of synaptic activation and is not preexisting $\operatorname{Arc}$ mRNA that relocalizes from inactive dendritic domains; (3) the selective localization of ARC protein in the region of active synapses is dependent on local translation of localized Arc mRNA; (4) $\alpha C a M K I I$ mRNA is not subject to activity-dependent mRNA decay, at least within the same time frame as $A r c$; (5) the same pattern of synaptic activity also causes $\alpha$ CaMKII mRNA to accumulate near active synapses; (6) although both $A r c$ and $\alpha C a M K I I$ mRNAs accumulate at active synapses, the two mRNAs are in completely different particles; and (7) translation-dependent Arc mRNA degradation occurs during periods in which Arc transcription is induced by physiologically relevant learning experiences. These results provide several important new insights into the mechanisms through which synaptic activity regulates mRNA localization in dendrites and local synthesis of protein at synapses.

Differential localization of Arc mRNA is the combined result of targeting newly synthesized Arc mRNA to active domains and degradation throughout dendrites

The relative roles of targeting versus degradation are revealed by the combined results of experiments involving inhibitors of transcription and translation. The first important point is that, when transcription is inhibited, there is no accumulation of Arc mRNA in the activated lamina, although Arc mRNA was already present throughout dendrites. The fact that the band does not develop in the presence of ActD means that relocalization cannot account for the accumulation that occurs. Thus, the Arc mRNA that localizes selectively in the region of the active synapses is newly transcribed.

Second, with ongoing synaptic activity, Arc mRNA is degraded, and this degradation is blocked by protein synthesis inhibitors. In the region of protein synthesis blockade, levels of Arc mRNA increased throughout cell bodies and dendrites as a consequence of PP stimulation, but the greatest increase in Arc mRNA was precisely in the region of activated synapses. Thus, newly synthesized Arc mRNAs localize near active synapses and undergo both translation and high levels of translation-dependent degradation. Despite high levels of translation-dependent degradation in the region of activated synapses, the net result is preferential depletion from inactive dendritic domains because of the simultaneous preferential targeting of newly synthesized Arc mRNA to the active region. Thus, the overall pattern of localization (high in active domains, low in inactive domains) is the combined result of activity-dependent degradation throughout 
dendrites and targeting of new mRNA to the region of active synapses.

Importantly, although transcription continues for hours after ECS, synaptic stimulation boosts transcription further while simultaneously driving down overall levels of Arc mRNA in dendrites. Therefore, Arc mRNA degradation is being enhanced on the side of PP stimulation, and this enhanced degradation is occurring mostly in the zone of activated synapses.

\section{Is $\operatorname{Arc}$ mRNA degradation a result of NMD?}

The translation-dependent degradation of Arc mRNA that we show here is consistent with the report by Giorgi et al. (2007). However, except for the dependence on translation, our data do not provide additional evidence for the hypothesis that degradation occurs via an NMD-like mechanism as proposed by Giorgi et al. However, recent findings propose that mammalian NMD targets could be regulated according to cellular cues to switch from being actively translated to being degraded via NMD (Durand and Lykke-Andersen, 2013). This type of mechanism would be well suited for the temporal and spatial control required for Arc. Translation-dependent degradation has been described for other IEGs, such as $c-M y c$ and $c$-Fos, in parallel with poly(A) tail shortening (Wilson and Treisman, 1988; Laird-Offringa et al., 1990). Also, inhibition of translation can lead to super-induction of transcription (Cochran et al., 1983; Lau and Nathans, 1987), in which protein synthesis inhibitors, in the presence of growth factors or other stimulating agents, augment and prolong expression of IEGs. Importantly, super-induction of transcription cannot explain the fact that the largest increase in Arc mRNA levels in the presence of $\mathrm{CHX}$ is in the activated dendritic domain, leaving synaptically driven, protein synthesis-dependent degradation as the plausible explanation.

\section{Differential distribution of ARC protein depends on sustained local synthesis}

In the ECS-PP stimulation paradigm, the distribution of ARC protein closely matches the distribution of Arc mRNA. This applies to both the accumulation of ARC protein in the activated lamina and the decreases in the inactive laminae. Given that ARC protein is present in the inactive laminae at the start of synaptic stimulation, our results suggest that ARC protein turns over very quickly so that levels depend directly on the local levels of Arc mRNA. Therefore, the only reason that ARC protein levels remain high with PP stimulation is that Arc mRNA is continuously delivered to the activated domain and locally translated so that ARC protein levels are continuously refreshed.

The fact that Arc mRNA and protein accumulate in the activated dendritic lamina is paradoxical given other recent evidence that newly synthesized ARC protein localizes selectively at inactive rather than active synapses (Okuno et al., 2012). In our setting, strong activation of one set of synapses causes ARC protein to accumulate in the activated domain and disappear from the inactive domains. However, it is important to note two facts. First, Okuno et al. report shifts of ARC protein from dendritic shafts to the postsynaptic density (PSD) rather than longerdistance movement of ARC protein from one dendritic domain to another. Our studies show that Arc mRNA and protein are present in the dendritic lamina near the activated synapses but do not reveal whether the protein is in the dendritic shaft or the PSD. Second, it is likely that our PP stimulation paradigm activates only some of the synapses in the middle molecular layer, so that active and inactive synapses are present on the same dendritic segments. It is possible that the ARC protein in the activated lamina is localized selectively at the inactive population of synapses that are intermixed with the active ones. The other possibility is that stimulation of the PP induces a form of LTP that requires ARC at activated synapses as well as perhaps some form of homeostatic scaling at inactive synapses. Additional studies are needed to explore how ARC protein participates in multiple forms of synaptic plasticity.

\section{$\alpha C a M K I I$ mRNA accumulates near active synapses but does} not undergo activity-dependent mRNA degradation

One surprising finding was that $\alpha C a M K I I$ mRNA also accumulates in the activated dendritic domain. Previous studies showed that $\alpha$ CaMKII mRNA moves from the dendrite into the synaptodendrosomal fraction in response to PP LTP in adult awake rats (Håvik et al., 2003), but accumulation in active dendritic domains has not been reported previously. It should be noted that we did not detect an accumulation of $\alpha C a M K I I$ mRNA near active synapses in our original study (Steward et al., 1998). This is likely attributable to the fact that the FISH techniques used here are more sensitive than the non-isotopic colorimetric ISH technique used in our original study. Importantly, $\alpha C a M K I I$ is not depleted with prolonged synaptic activation. Additionally, we did not detect any increase in $\alpha C a M K I I$ mRNA when translation was blocked either with or without synaptic stimulation. Thus, the mRNA decay mechanisms we describe here do not operate on another dendritic mRNA. Additional studies will be required to determine whether $A r c$ is completely unique in this regard.

\section{$A r c$ and $\alpha C a M K I I \mathrm{mRNAs}$ are in different particles}

mRNAs are transported in discrete granules (Kiebler and Bassell, 2006). Evidence from subcellular fractionation experiments suggests that $A r c$ and $\alpha$ CaMKII mRNAs are present in particles of similar size and biochemical composition (Kanai et al., 2004), but it was unknown previously whether the two mRNAs were colocalized in the same individual particle. Our double-labeled ISH studies reveal that there is very little colocalization, at least under conditions in which Arc is strongly induced. These data are in agreement with other studies that show that neuronal mRNAs, even those with common dendritic localization sequences, are independently transported into dendrites and in low copy numbers (Mikl et al., 2011; Batish et al., 2012).

Our results support the idea that regulation of mRNA metabolism in dendrites influences local protein synthesis and synaptic plasticity (for review, see Kiebler and Bassell, 2006; Swanger and Bassell, 2011). For example, recent findings show that certain micro-RNAs and members of the RNA-induced silencing complex pathway are negatively regulated by activity, leading to the local translational release of micro-RNA targets, $\alpha C a M K I I$ and PSD-95, at synapses (Ashraf et al., 2006; Banerjee et al., 2009; Muddashetty et al., 2011). Our finding that newly transcribed Arc mRNAs undergo activity-induced degradation near activated synapses that is tightly coupled to translation reveals previously unknown mechanisms for strict spatial and temporal control over local translation.

\section{References}

Ashraf SI, McLoon AL, Sclarsic SM, Kunes S (2006) Synaptic protein synthesis associated with memory is regulated by the RISC pathway in Drosophila. Cell 124:191-205. CrossRef Medline

Banerjee S, Neveu P, Kosik KS (2009) A coordinated local translational control point at the synapse involving relief from silencing and MOV10 degradation. Neuron 64:871-884. CrossRef Medline

Batish M, van den Bogaard P, Kramer FR, Tyagi S (2012) Neuronal mRNAs 
travel singly into dendrites. Proc Natl Acad Sci U S A 109:4645-4650. CrossRef Medline

Cochran BH, Reffel AC, Stiles CD (1983) Molecular cloning of gene sequences regulated by platelet-derived growth factor. Cell 33:939-947. CrossRef Medline

Durand S, Lykke-Andersen J (2013) Nonsense-mediated mRNA decay occurs during eIF4F-dependent translation in human cells. Nat Struct Mol Biol 20:702-709. CrossRef Medline

Gao Y, Tatavarty V, Korza G, Levin MK, Carson JH (2008) Multiplexed dendritic targeting of $\alpha$ calcium calmodulin-dependent protein kinase II, neurogranin, and activity-regulated cytoskeleton-associated protein RNAs by the A2 pathway. Mol Biol Cell 19:2311-2327. CrossRef Medline

Giorgi C, Yeo GW, Stone ME, Katz DB, Burge C, Turrigiano G, Moore MJ (2007) The EJC factor eIF4AIII modulates synaptic strength and neuronal protein expression. Cell 130:179-191. CrossRef Medline

Guzowski JF, McNaughton BL, Barnes CA, Worley PF (1999) Environmentspecific expression of the immediate-early gene Arc in hippocampal neuronal ensembles. Nat Neurosci 2:1120-1124. CrossRef Medline

Guzowski JF, Lyford GL, Stevenson GD, Houston FP, McGaugh JL, Worley PF, Barnes CA (2000) Inhibition of activity-dependent Arc protein expression in the rat hippocampus impairs the maintenance of long-term potentiation and the consolidation of long-term memory. J Neurosci 20:3993-4001. Medline

Guzowski JF, Miyashita T, Chawla MK, Sanderson J, Maes LI, Houston FP, Lipa P, McNaughton BL, Worley PF, Barnes CA (2006) Recent behavioral history modifies coupling between cell activity and Arc gene transcription in hippocampal CA1 neurons. Proc Natl Acad Sci U S A 103: 1077-1082. CrossRef Medline

Håvik B, Røkke H, Bårdsen K, Davanger S, Bramham CR (2003) Bursts of high-frequency stimulation trigger rapid delivery of pre-existing $\alpha$-CaMKII mRNA to synapses: a mechanism in dendritic protein synthesis during long-term potentiation in adult awake rats. Eur J Neurosci 17:2679-2689. CrossRef Medline

Huang F, Chotiner JK, Steward O (2007) Actin polymerization and ERK phosphorylation are required for Arc/Arg3.1 mRNA targeting to activated synaptic sites on dendrites. J Neurosci 27:9054-9067. CrossRef Medline

Kanai Y, Dohmae N, Hirokawa N (2004) Kinesin transports RNA: isolation and characterization of an RNA-transporting granule. Neuron 43:513525. CrossRef Medline

Kandel ER (2001) The molecular biology of memory storage: a dialogue between genes and synapses. Science 294:1030-1038. CrossRef Medline

Kiebler MA, Bassell GJ (2006) Neuronal RNA granules: movers and makers. Neuron 51:685-690. CrossRef Medline

Laird-Offringa IA, de Wit CL, Elfferich P, van der Eb AJ (1990) Poly(A) tail shortening is the translation-dependent step in c-myc mRNA degradation. Mol Cell Biol 10:6132-6140. CrossRef Medline

Lau LF, Nathans D (1987) Expression of a set of growth-related immediate early genes in BALB/c 3T3 cells: coordinate regulation with c-fos or c-myc. Proc Natl Acad Sci U S A 84:1182-1186. CrossRef Medline

Link W, Konietzko U, Kauselmann G, Krug M, Schwanke B, Frey U, Kuhl D (1995) Somatodendritic expression of an immediate early gene is regulated by synaptic activity. Proc Natl Acad Sci U S A 92:5734-5738. CrossRef Medline
Lyford GL, Yamagata K, Kaufmann WE, Barnes CA, Sanders LK, Copeland NG, Gilbert DJ, Jenkins NA, Lanahan AA, Worley PF (1995) Arc, a growth factor and activity-regulated gene, encodes a novel cytoskeletonassociated protein that is enriched in neuronal dendrites. Neuron 14:433445. CrossRef Medline

Messaoudi E, Kanhema T, Soulé J, Tiron A, Dagyte G, da Silva B, Bramham CR (2007) Sustained Arc/Arg3.1 synthesis controls long-term potentiation consolidation through regulation of local actin polymerization in the dentate gyrus in vivo. J Neurosci 27:10445-10455. CrossRef Medline

Mikl M, Vendra G, Kiebler MA (2011) Independent localization of MAP2, CaMKII $\alpha$ and $\beta$-actin RNAs in low copy numbers. EMBO Rep 12:10771084. CrossRef Medline

Muddashetty RS, Nalavadi VC, Gross C, Yao X, Xing L, Laur O, Warren ST, Bassell GJ (2011) Reversible inhibition of PSD-95 mRNA translation by miR-125a, FMRP phosphorylation, and mGluR signaling. Mol Cell 42: 673-688. CrossRef Medline

Nguyen PV, Kandel ER (1996) A macromolecular synthesis-dependent late phase of long-term potentiation requiring cAMP in the medial perforant pathway of rat hippocampal slices. J Neurosci 16:3189-3198. Medline

Okuno H, Akashi K, Ishii Y, Yagishita-Kyo N, Suzuki K, Nonaka M, Kawashima T, Fujii H, Takemoto-Kimura S, Abe M, Natsume R, Chowdhury S, Sakimura K, Worley PF, Bito H (2012) Inverse synaptic tagging of inactive synapses via dynamic interaction of $\operatorname{Arc} / \operatorname{Arg} 3.1$ with CaMKII $\beta$. Cell 149:886-898. CrossRef Medline

Park S, Park JM, Kim S, Kim JA, Shepherd JD, Smith-Hicks CL, Chowdhury S, Kaufmann W, Kuhl D, Ryazanov AG, Huganir RL, Linden DJ, Worley PF (2008) Elongation factor 2 and fragile X mental retardation protein control the dynamic translation of Arc/Arg3.1 essential for mGluR-LTD. Neuron 59:70-83. CrossRef Medline

Shan J, Munro TP, Barbarese E, Carson JH, Smith R (2003) A molecular mechanism for mRNA trafficking in neuronal dendrites. J Neurosci 23: 8859-8866. Medline

Steward O, Worley PF (2001) Selective targeting of newly synthesized Arc mRNA to active synapses requires NMDA receptor activation. Neuron 30:227-240. CrossRef Medline

Steward O, Wallace CS, Lyford GL, Worley PF (1998) Synaptic activation causes the mRNA for the IEG Arc to localize selectively near activated postsynaptic sites on dendrites. Neuron 21:741-751. CrossRef Medline

Swanger SA, Bassell GJ (2011) Making and breaking synapses through local mRNA regulation. Curr Opin Genet Dev 21:414-421. CrossRef Medline

Vazdarjanova A, Guzowski JF (2004) Differences in hippocampal neuronal population responses to modifications of an environmental context: evidence for distinct, yet complementary, functions of CA3 and CA1 ensembles. J Neurosci 24:6489-6496. CrossRef Medline

Wallace CS, Lyford GL, Worley PF, Steward O (1998) Differential intracellular sorting of immediate early gene mRNAs depends on signals in the mRNA sequence. J Neurosci 18:26-35. Medline

Wang F, Flanagan J, Su N, Wang LC, Bui S, Nielson A, Wu X, Vo HT, Ma XJ, Luo Y (2012) RNAscope: a novel in situ RNA analysis platform for formalin-fixed, paraffin-embedded tissues. J Mol Diagn 14:22-29. CrossRef Medline

Wilson T, Treisman R (1988) Removal of poly(A) and consequent degradation of c-fos mRNA facilitated by 3' AU-rich sequences. Nature 336:396399. CrossRef Medline 